\title{
Order aggressiveness of different broker-types in response to monetary policy news
}

\section{Lee A. Smales, CFA}

\author{
School of Economics \& Finance, Curtin University, Perth, WA 6102, Australia
}

Email: lee.smales@curtin.edu.au

\begin{abstract}
This paper examines the pattern of order aggressiveness, and the determinants of this pattern for institutional and retail brokers in the interval around monetary policy announcements. Utilizing a high-frequency dataset, with broker identifiers for each order submitted on the ASX over the period Dec 2007 - Dec 2014, I identify a sharp increase in the number of orders submissions in the period following RBA announcements. Orders are more aggressive, and more abundant, when there is less information for investors to digest. On average, retail orders are more aggressive and are exclusively concerned with the likelihood of order execution. The submission decision of institutional brokers is more nuanced and evolves over time as market conditions change and information arrives. I also recognize differences in order aggressiveness attributable to firm-size and industry.
\end{abstract}

Keywords: Order aggressiveness, Limit order book, Institutional brokers, Retail brokers, Monetary policy news, Reserve Bank of Australia

JEL Classification: G1, G10, G11, G14, G15, G20

Acknowledgements: I would like to acknowledge the Securities Industry Research Centre of AsiaPacific (SIRCA) for the provision of data utilised in this study. I would also like to thank an anonymous referee and discussants at the 2016 Financial Markets and Corporate Governance Conference (particularly Joakim Westerholm and Phil Gray) for their insightful comments which have served to improve this paper. All remaining errors are mine. 


\section{Order aggressiveness of different broker-types in response to monetary policy news}

Abstract: This paper examines the pattern of order aggressiveness, and the determinants of this pattern for institutional and retail brokers in the interval around monetary policy announcements. Utilizing a high-frequency dataset, with broker identifiers for each order submitted on the ASX over the period Dec 2007 - Dec 2014, I identify a sharp increase in the number of orders submissions in the period following RBA announcements. Orders are more aggressive, and more abundant, when there is less information for investors to digest. On average, retail orders are more aggressive and are exclusively concerned with the likelihood of order execution. The submission decision of institutional brokers is more nuanced and evolves over time as market conditions change and information arrives. I also recognize differences in order aggressiveness attributable to firm-size and industry.

\section{Introduction}

Stock market investors face an important trade-off when entering orders into a limit order book. Market orders (or marketable limit orders) have the advantage of immediate order execution, but at the price of higher execution costs. On the other hand, limit orders present price improvements but have an increased risk of non-execution. This study investigates the pattern of order aggressiveness of institutional and retail brokers, and the factors that determine this pattern, in the period around monetary policy announcements by the Reserve Bank of Australia (RBA).

A broad literature has attempted to empirically examine this choice of order placement and aggression level. Biasis et al. (1995), Ranaldo (2004), Hall and Hautsch (2006), Aitken et al. (2007a), and Duong et al. (2009) are among those that identify a relationship between order aggressiveness and market depth, bid-ask spreads and volatility. Griffiths et al. (2000) find that aggressive orders have a large price impact but smaller opportunity costs than passive orders; such price impacts are amplified by order size, firm size, and market volatility. Lo and Sapp (2010) find that information asymmetry and liquidity play an important role in the choice of order aggressiveness. This study contributes to this discussion by focusing on the period around monetary policy announcements. The institutional setting surrounding such announcements is interesting to study since there is likely to be a low level of information asymmetry prior to the announcement. Therefore, any trading advantage, and difference in the order submission process, will likely arise as a result of the ability to interpret announcements, and the speed in implementing investment decisions. 
Sakar and Schwartz (2009) infer motives for trade initiation on the basis of market sidedness, which is determined by the correlation between buy-side and sell-side trade initiations (an increased (decreased) correlation indicated that trading is more two-sided (one-sided)). They argue that trading motivated by asymmetric information generates more one-sided markets, whereas trading motivated by differential information / beliefs leads to more two-sided markets. Results suggest that more two-sided markets are observed after news releases, especially when the news surprises are large; such markets are generally, but not always, associated with lower order imbalance.

If the same patterns are realised in the period around monetary policy announcements, then we may expect to see declining order submission prior to the announcement, and more twosided markets following the announcement. Order aggressiveness of retail traders should not expected be to be influenced by the presence of a monetary policy announcement, although this is contrary to the results reported here. The order aggressiveness expected by informed institutions is unclear; Aitken et al. (2007b) suggest they should be more aggressive where an information advantage is perceived, while Bloomfield et al. (2005) suggest a lower level of aggression through the use of limit orders. The empirical results presented in this paper are more supportive of the latter argument.

Understanding the order submission process is important since it can provide insights into market efficiency, and the conditions under which liquidity is supplied and demanded by market participants. Additionally, been cognizant of the determinants of order submission strategies allows optimization, which Harris (1998) suggests will result in lower transaction costs and higher portfolio returns. Since macroeconomic news in general, and monetary policy news in particular, has a significant bearing on the stock market, it is intuitive to expect that policy news may also be a factor influencing the appropriate level of order aggression. It is possible that proximity to such news, which has a significant impact on volatility, may induce panic in investors who may then be less concerned with price and more concerned with execution certainty, the result being more aggressive orders. Alternatively, investors may be concerned with getting "picked-off" in a fastmoving market and so make greater use of less aggressive limit orders.

Through the use of Australian data, which has unique properties regarding the identification of brokers and the centralization of trading, I am able to gain an insight into this important process that will be applicable to monetary policy events elsewhere, and to 
macroeconomic news more generally. Using an empirical set-up that is closest to that of Ranaldo (2004) and Duong et al. (2009), I find the following key results. First, there is a sharp increase in order submission as market participant assimilate information in the period immediately following RBA target rate announcement. The scale of the jump in orders dependent on both the magnitude and direction of the surprise component of the announcement; orders are more aggressive, and more prevalent, when there is less information for participants to digest (for instance when the target rate is predictably unchanged). Second, there is a distinction in the order submission choice for institutional and retail brokers. Institutional brokers are concerned with both the likelihood and cost of order execution. Aggression of order submission is reduced whenever the likelihood of execution is improved, or the cost of execution (e.g. bid-ask spreads) rises.

The dynamic order submission process for institutional brokers is consistent with the evolving liquidity provision of Bloomfield et al. (2005), the possibility of information asymmetry, and the desire to avoid been "picked-off" (Foucalt, 1999). A simple experiment suggests that an information advantage is the most likely explanation. On the other-hand, retail brokers appear to be solely concerned with certainty of execution and thus are more aggressive. Third, there is a variation in the observed order submission pattern, and the determinants of that pattern, for large-cap firms on one-side and mid-cap and small-cap on the other. Similarly, there is a difference for financial and non-financial firms, with institutional (retail) brokers acting more aggressively in stocks of financial (non-financial) firms. Finally, both institutional and retail orders are rational to the extent that there is less willingness to buy (sell) ahead of target rate decisions which are expected to produce falling (rising) share prices. That is, when the rates are expected to increase (decrease) then buy (sell) orders are less aggressive.

The remainder of this paper is organized as follows: Section 2 highlights the salient literature in this field. Section 3 discusses the data utilized in the empirical analysis, and describes the process by which brokers are classified, orders aggressiveness is categorized, and RBA target rate surprises are determined. Section 4 presents the empirical analysis and Section 5 discusses the implications of the results. Section 6 concludes the paper. 


\section{Literature Review}

Most models of trading behaviour assume a homogeneous interpretation of information. However, it is possible that information asymmetry may arise owing to the release of public information such as macroeconomic announcements or important corporate announcements (e.g. earnings, takeovers, or bond rating changes). Chae (2005) investigates trading volume in the period around corporate events and demonstrates that, consistent with decreasing volume in periods of high adverse selection costs, trading volume is negatively (positively) correlated with levels of information asymmetry before (after) scheduled announcements. This is consistent with Bessembinder et al. (1996) who report a higher level of market activity when opinions diverge, and Kandel and Pearson's (1995) assumption that traders differ in their interpretation and this induces trading. Griffiths et al. (2000) find that aggressive orders are motivated by information. This is supported by Aitken et al. (2007b) who report that institutions are more aggressive than other traders in an attempt to benefit from any short-lived information advantage, while retail traders are less aware of the market state when placing aggressive orders. On the other hand, Bloomfield et al. (2005) note that informed traders use more limit orders than do liquidity traders.

The literature has established that macroeconomic news announcements, particularly those related to monetary policy decisions, have a significant impact on measures of market activity, liquidity, and volatility. Monetary policy may affect asset prices through interest rate and / or credit channels, and so announcements relating to policy decisions may be considered likely to impact trading decisions. U.S. markets respond to the actual (Cook and Hahn, 1989) and surprise (Kuttner, 2001; Fatum and Scholnick, 2008) component of the Federal Reserve as well as communication about future policy actions (Gurkaynak, Sack, and Swanson, 2005). Bernanke and Kuttner (2005) seek to identify specific factors that affect the response, such as distinguishing between scheduled and unscheduled changes. They speculate that intermeeting moves convey more urgency and so have larger impact on financial markets. Fleming and Piazzesi (2005) show that market liquidity in the period around FOMC decisions behaves in a similar manner to that found for other macroeconomic announcements.

Erenburg et al. (2006) report a large increase in trading activity immediately after macroeconomic announcements, with local traders reacting faster than off-exchange traders. Ruhl and Stein (2015) find that bid-ask spreads are significantly affected by monetary policy announcements with the effect strongest for announcements that comprise unexpected 
information. The identified response is rapid; Ederington and Lee $(1993,1995)$ and Fleming and Remolona (1999) analyze the impact of macroeconomic news on the U.S. interest rate and foreign exchange markets and report that most of the reaction is complete within the first minute of the news release. Frino and Hill (2001) and Smales (2013) describe similar results for Australian stock index futures and interest rate futures.

The literature concerning the effect of macroeconomic news on specific types of investors is more limited. Nofsinger (2001) investigates the trading behaviour of both institutional and retail investors in the period around firm-specific and macroeconomic news releases. He identifies a response that is concentrated in large firms, such that investors conduct a high proportion of trading around news releases, with institutions responding to both good and bad news, while retails investors only trade in response to good news.

It is likely that the choice of order aggressiveness evolves over time and this has implications for market efficiency and price formation. Bloomfield et al. (2005) find that liquidity provision develops as trading progresses in an experimental setting. Informed traders provide liquidity in response to the price adjustment to new information, taking liquidity when the value of their information is high, and providing liquidity when the value is low. Lebedeva (2014) notes an increase in trading aggressiveness after public news and examines the influence of this on the speed of price adjustment. She argues that an increase in trading aggressiveness may allow for quick price changes that are beneficial, but can also slow down the price adjustment process is such orders are mostly used by uninformed traders to transact on their heterogenous beliefs. In this case, there would be a cost to the market in terms of an increased chance of price overshooting and higher than necessary volatility.

Ranaldo (2004) analyzes the information content of the limit order book for the Swiss stock exchange. He shows that patient traders become more aggressive when the same- (opposite) side book is thicker (thinner), the spread wider, and volatility increases. There is also evidence of order submission varying for buy and sell orders. Duong et al. (2009) are able to utilize unique reporting characteristics of the Australian market to identify similar results for orders identified as belonging to institutional and retail brokers.

The empirical evidence is supported by the theoretical models of Harris (1998), Parlour (1998), Foucalt (1999) and Handa et al. (2003) among others. Harris (1998) derives optimal order 
submission strategies for three stylized traders. His model highlights the important relationship between time and price in the search for liquidity. Parlour (1998) focuses on the choice between demanding liquidity through the placement of market orders (or marketable limit orders) and supplying liquidity by submitting limit orders. Examining the costs and determinants of order aggressiveness, the model highlights that the decision to submit a market order or a limit order depends on the market depth on either side of the order book. Aggressive orders are then more likely to be motivated by information. Foucalt (1999) provides a game-theoretic model and obtains closed-form solutions for order placement strategies in equilibrium. Limit orders results in better execution prices but face the risk of non-execution and a winners' curse problem ("pickedoff'). In this framework volatility is recognized as the key determinant of the choice between market and limit orders. Handa et al. (2003) model quote-setting in an order driving market where trading occurs because investors have heterogenous beliefs about valuation levels and the advent of news is not common knowledge. The size of the spread, and associated liquidity, is then a function of the differences in valuation and adverse selection.

\section{Data}

I investigate the determinants of order aggressiveness in the period surrounding RBA cash target rate announcements for 30 large-cap, 30 mid-cap, and 30 small-cap stocks traded on the Australian Securities Exchange (ASX); a consolidated electronic limit order book market. To avoid complications arising from a regime change in RBA monetary policy communication, the sample of policy decisions starts on 05 December 2007; from this date the RBA has issued a statement explaining their decision following all monetary policy meetings rather than solely those meetings that result in a change in the target rate. The sample period ends on 02 December 2014. The empirical study focuses on the period immediately surrounding each RBA announcement.

\subsection{Stock Selection and Data}

Stocks are selected on the basis of stock market capitalisation and trading activity. First, I consider only seasoned common stocks so that all unit trusts, preference shares, and stocks with less than 3-years of trading history are excluded from the sample. Second, I require that all the stocks under investigation must be included in the S\&P/ASX 200 index on 04 December 2007 (the day prior to the start of the sample period) and 02 December 2014 (the end of the sample period). The choice of the S\&P/ASX 200 index ensures the representation of large-cap, mid-cap, and 
small-cap stocks as well as the institutional trading interest and the liquidity of the stocks considered. Consistent with ASX classification, large-cap stocks are defined as the stocks which are included in the S\&P/ASX 50 index. Mid-cap stocks are defined as stocks included in the S\&P/ASX 100 index but not in the S\&P/ASX 50 index. Similarly, small-cap stocks are defined as those included in the S\&P/ASX 200 index but not in the S\&P/ASX 100 index. Third, I rank all large-cap, mid-cap, and small-cap stocks based on the daily average number of trades for the three-month period prior to the sample period. The chosen 30 large-cap stocks are the 30 most traded large-cap stocks, and the chosen 30 small-cap stocks are the 30 least traded small-cap stocks. The 30-mid cap stocks are selected as the 15 stocks directly above and below the mean daily average number of trades. Approximately $20 \%$ of the firms in each category are designated as financial (determined by the 2-digit GICS sector code). Large-cap firms exhibit more liquidity, so have lower non-execution risk, and are more closely monitored than mid-cap and small-cap firms. By examining stocks of varying firm size the generalizability of results is improved.

Table 1, Panel A, provides descriptive statistics for the stocks considered in this study. The average market capitalisation of large-cap firms at $\$ 25.5$ billion is over ten times greater than that of mid-cap firms, and 28 times greater than small-cap firms. Consistent with the literature, trading volume, whether measured by number of trades or value of trades, is highest for large-cap stocks and lowest for small-cap stocks, while the opposite is true for relative spreads.

Order-book and market depth data are obtained from the Securities Industry Research Centre of Asia-Pacific (SIRCA). The Order-Book dataset records details on each order, including the order type (order submission, order revision, order cancellation and execution), the date and time to the nearest hundredth of a second, instrument code, order price, order volume and order direction (buy or sell). Each new order is assigned a unique identification number to enable tracking from submission through to revision, cancellation, or execution. A unique feature of this dataset is the broker code identifier which allows the classification of orders as those submitted by institutional or retail broker-types.

The Market Depth dataset contains information on the market depth of a particular stock. Specifically, it details the 10 best limit prices on the bid- and ask-side, together with the total volume at each price level. I remove all the observations in the dataset whenever the bid price is greater than the ask price at any of the 10 limit price levels. I also exclude all observations where the bid (ask) prices are not in strict descending (ascending) order from the first to the tenth best 
prices. By combining the two datasets, I arrive at a final dataset containing detailed information on every order submitted, revised or cancelled together with the market depth information at the time of the order. In this study, only the orders submitted in the main trading session (from 10:10 to 16:00) on the day of an RBA target rate decision are included. Following Duong et al. (2009), I exclude crossing orders, All or Nothing orders and Fill and Kill orders from the analysis. This paper seeks to understand the decision to enter an order into the order book given market conditions. As such, limit orders which are revised are treated as a new order, while orders that are cancelled (which frequently occur) are treated as an order at the time of initial submission but the subsequent cancellation is excluded from the sample.

The focus on Australian securities offers three distinct advantages. First, I am able to determine the name of the broker that entered any given order into the order book and subsequently classify each order as emanating from a particular broker-type. Second, the ASX has been a consolidated order book for the vast majority of the sample period ${ }^{12}$, and there is no payment for order flow as in the United States. Third, with a sample period of RBA meetings over 8 calendar years, the data set covers a sample period that is longer than those used in other studies.

\subsection{Broker Classification and Order Aggressiveness}

The main purpose of this study is to develop an understanding of the difference in order aggressiveness of order places by institutional and retail broker types. In order to undertake this analysis, the broker code identifiers in the data provided by SIRCA must be classified appropriately. I follow the approach of Fong et al. (2014) in assigning classifications on the basis of brokers' names and the description of the brokers' activities and services provided through their websites, news articles, or telephone interview. The step-by-step process is detailed in Appendix A.

\footnotetext{
${ }^{1}$ Chi-X entered the Australian market as a trading platform in November 2011 and remains the only competitor to the ASX. The total proportion of trading volume has remained $15 \%$ or less in the intervening period, as opposed to the fragmentation witnessed in other markets such as the U.S.

${ }^{2}$ In order to investigate the impact of the introduction of Chi-X on the reported results, the empirical analysis is repeated with two sub-samples: pre-November 2011 and post-November 2011. The results are qualitatively similar (the main difference is a small $\sim 2 \%$ increase in the proportion of limit orders by retail brokers, and slightly greater use of level 5 as opposed to level 6 limit orders) and so only the results for the whole sample are reported in the main text of the paper. A summary of the results for the two sub-samples described here is available from the author upon request.
} 
Order Aggressiveness for each order is assigned on the basis of the six categories identified in Biais et al. (1995). Category 1 orders are the most aggressive type, they are buy (sell) orders with prices greater (less) than the best ask (bid) quote and the size of the order exceeds the market depth at the best ask (bid) quote. These bid (ask) orders are executed against the volume at the ask (bid) and in part against the market depth available higher (lower) in the book up to the order price. The unfilled portion of the order enters as a limit order in the order book. Category 2 orders are buy (sell) orders with prices equal to the best ask (bid) quote and demand more volume than the market depth at the best ask (bid) quote. These orders are executed immediately and the unfilled portion of the order becomes a limit order at that price in the limit order book. Category 3 orders are orders with price equal to the opposite best quote and demand less volume than the market depth at the opposite best quote. These orders are executed immediately and in full. Category $4^{3}$ orders are limit orders within the prevailing quotes, while Category 5 orders are placed at the prevailing quote. Category 6 orders are buy (sell) orders placed below (above) the prevailing quote and are the least aggressive.

Categories 1, 2 and 3 are marketable limit orders that result in immediate execution and are thus analogous to market orders for immediate execution at posted prices in a specialist or dealer market such as the New York Stock Exchange. Categories 4, 5 and 6 are limit orders, as they are not executed immediately.

Descriptive statistics for order aggressiveness and related market conditions at the time of order submission are provided in Table 1, Panel B. The least aggressive limit orders (categories 5 and 6) are most prevalent for both institutional and retail investors. The next most common orders are in category 3; such orders, which are filled in full, are generally small and submitted when depth on the opposite side of the quote is large. Category 2 orders have the largest order size which may explain why they are not filled in full.

$<$ Insert Table 1>

\footnotetext{
${ }^{3}$ In June 2010, the ASX established Centre Point, which allows market participants to execute orders anonymously at the prevailing mid-point of the national best bid and offer. This may affect the classifying of orders as Category 4 . He and Lepone (2014) note that less than $1 \%$ of total trade volume is executed through Centre Point, while I categorise only 1.1\% (2.7\%) of institutional (retail) trades as Category 4. A robustness test on orders when the prevailing bid-ask spread is greater than one tick produces results that are similar to those reported here - the distribution of order submissions is available from the author upon request.
} 


\subsection{RBA Cash Target Rate Surprise}

The overnight cash rate target is the primary monetary policy tool of the Reserve Bank of Australia (RBA) and, following a meeting of the Reserve Bank Board, an announcement of the target rate decision is made at 14:30 (AEST) on the first Tuesday of each month other than January. Consistent with the notion of efficient markets, I would expect the order submission pattern to be affected only by the unexpected or surprise component of the announcement. Smales (2012a) augments the methodology of Kuttner (2001) to make use of the fact that the RBA is able to maintain the interbank overnight cash rate very close to the target, together with the availability of 30-day interbank futures contracts, to derive explicit ex-ante expectations on RBA target rate decisions. I utilise this method to calculate the RBA cash target rate surprise as:

$$
\begin{aligned}
& R B A_{\text {Surprise }}=\Delta \text { Target Rate }-E[\Delta \text { Target Rate }] \\
& E[\Delta \text { Target Rate }]=E\left[R_{\text {post }}\right]-R_{\text {prior }}=\frac{D_{m} \times R_{I B}-D_{\text {pre }} \times R_{\text {prior }}}{D_{\text {post }}}
\end{aligned}
$$

Where $R_{I B}$ is the rate implied from the front-contract interbank future, $R_{\text {post }}$ is the RBA target rate post announcement, $R_{\text {prior }}$ is the RBA target rate applicable immediately prior to the announcement, $D_{m}$ is the total number of days in the month in which the announcement takes place, $D_{\text {pre }}$ is the number of days in the month prior to the announcement date, and $D_{\text {post }}$ is the number of days following the announcement for which the announced target rate will be effective.

During the December 2007 - December 2014 sample period the RBA made 78 target rate decisions, resulting in 14 reductions in the target rate (averaging 46.4 basis points), 9 increases in the target rate (each of 25 basis points), and 55 occasions on which rates were left unchanged. The market may be surprised by decisions that result in easier (tighter) than expected policy should the RBA reduce (increase) the target rate by more than the expected amount, leave the rate on hold when a hike (cut) is expected, or increase (decrease) the rate less than expected. Owing to the bid-ask spread in 30-day interbank futures I denote market pricing of less than 2 basis points as the market having expectations of no rate move. On this basis, the market was surprised by easier policy on 15 occasions with an average surprise of 10.8 basis points, and by tighter policy on 44 occasions with an average surprise of 5.7 basis points. $80 \%$ of the surprises related to tighter 
policy are a result of the RBA leaving the target rate on hold when the market expects some positive probability of a rate reduction.

\section{Empirical Results}

\subsection{Patterns in Order Aggressiveness}

Figure 1 illustrates the pattern of order aggressiveness by both retail and institutional broker types in terms of market orders (categories 1, 2 and 3) and limit orders (categories 4, 5 and 6). Note the reliance of both broker-types on the use of limit order submissions, and the much higher number of institutional orders ${ }^{4}$. For all order types there is a clearly identified spike in the number of order submissions in the minute following the announcement; this subsides within a five-minute period to a level that is higher than that witnessed in the 30-minute period prior to the announcement.

$<$ Insert Figure 1>

Focusing on the 15-minute interval immediately surrounding the RBA announcement (-5 $\mathrm{min},+10 \mathrm{~min})$, I am able to ascertain a clear picture of the distribution of order aggressiveness of both institutional and retail broker types (Table 2). Retail orders are more aggressive on average, with the proportion of market orders $50 \%$ greater than that for institutional orders. This additional aggression is most pronounced for category 1 and 2 orders, and particularly for the 2minute period immediately following the announcement. The pattern for both institutional and retail orders appears to be for a slight (statistically insignificant) fall in order aggressiveness in the 10-minutes following the announcement. However, the 1-minute interval immediately following the announcement at 14:30 provides an important contrast. In this period, as information is processed by the market, and the number of orders is greatest, there is a significant decrease in the order aggression of institutional brokers and a significant increase in the aggression of retail orders.

\section{$<$ Insert Table 2>}

I am able to compare the order aggressiveness on days with an announcement to that on days without an RBA announcement. I select a random sample of trading days that occur during the sample period. To ensure that the comparison is not influenced by a day of the week effect, I

\footnotetext{
${ }^{4} \mathrm{NB}$ : Institutional orders are depicted on the right-hand scale.
} 
use only trading days that occur on a Tuesday. The pattern of order aggressiveness on days without RBA target rate announcements is shown in Table 3. Consistent with Duong et al. (2009) I find that both institutional and retail orders tend to be more aggressive on days without a RBA announcement. This is consistent with the idea that investors are wary in the presence of the greater levels of uncertainty that occur on RBA announcement days.

$<$ Insert Table 3>

Effectively, retail orders are demanding a higher amount of liquidity and institutional brokers are providing it. An alternative way of considering this is that institutional brokers are more wary about been "picked-off" in fast-moving markets and so are making greater use of the least aggressive orders (category 6), while retail investors are more concerned about expediency of trade execution than price level. One way of testing this is to examine who acts as counterparty to trades that are executed as a result of submitted orders, particularly trades that are initiated by specific broker types.

The counterparty for trades executed by broker type is illustrated in Table 4. Panel A shows that the majority (approximately 85\%) of retail-broker, and institutional-broker, trades have an institutional-broker counterparty on the day of a RBA announcement. When trades are initiated by a retail broker, the proportion of trades with an institutional broker counterparty increases, supporting the idea that institutional orders provide liquidity to retail orders. For trades initiated by institutional brokers the proportion of trades with retail and institutional counterparties falls, replaced by trades with "other" brokers. Panel B provides similar information for the 5-minute period immediately following the RBA announcement. The pattern followed by retail brokers is similar, while Institutional orders have a greater proportion of orders executed against "other" brokers.

$<$ Insert Table 4> 


\subsubsection{Effect of Firm Size on Order Aggressiveness Pattern}

Table 5 dissects this order submission pattern further, partitioning the orders into those for small-cap, mid-cap, and large-cap stocks. For retail orders there is a similar pattern across all three firm sizes, such that the order aggressiveness increases markedly from the minute prior to the announcement until two minutes after the announcement when it reverts to some normal level. However, institutional orders in the largest, most liquid stocks appear to behave differently than those for small-cap and mid-cap stocks. For large-cap stocks, order aggression is significantly lower than usual in the 2-minutes prior to the announcement (over $50 \%$ of orders are in the least aggressive category 6) and then rises significantly immediately following the announcement before declining once more. For mid-cap and small-cap stocks, the reverse pattern is evidenced, with greater aggression prior to the meeting and less aggression afterwards. The different patterns identified for institutional orders suggest that liquidity concerns are a driver of order aggression.

\section{$<$ Insert Table 5>}

The literature concerning the effects of monetary policy decisions, and macroeconomic announcements more generally, on market activity indicates that order aggressiveness might be dependent on the direction of the target rate surprise. Figure 2 illustrates the pattern of order aggression for retail and institutional brokers across firm sizes, and for monetary policy decisions that are easier than expected, tighter than expected, and as expected. The number of orders in each interval is highest when the decision is 'as expected', in this sample this tends to occur when the market is expecting no change in the target rate and the RBA concurs. In such cases, there is relatively little information asymmetry and little effect on overall market activity. Notably, retail orders seem to react to an 'as expected' result much more than do institutional orders. For cases of decisions that are 'tighter than expected', which commonly result from the RBA not changing rates when the market was expecting a reduction, there is a significant spike in the number of orders and also in the proportion of more aggressive market orders. Once the initial response to the news has passed, the number of orders settles to a level higher than that preceding the announcement. Finally, the number of orders is lowest for cases when the decision is 'easier than expected', which commonly occur when the market is expecting a reduction in the target rate and the RBA exceeds expectations, although the proportionate jump in order volume and order aggression following the announcement is also the greatest. 
$<$ Insert Figure 2>

\subsubsection{Effect of Financial Firms on Order Aggressiveness Pattern}

Given the nature of financial firms, and the impact of changes in monetary policy on their earnings and stock price, it is natural to suppose that the pattern of order aggressiveness may differ from that of non-financial firms in the period around the announcement. Figure 3 illustrates the order submission choice for firms classified as financial and non-financial according to the 2-digit GICS sector code 5 . The pattern noted earlier appears to hold for both firm-types and broker-types, with the number of orders lower before the announcement, spiking at the announcement, and then maintaining a level that is higher than pre-announcement. Limit orders are again predominant for both broker-types, and for both firm-types. The proportionate jump in orders submitted by institutional $(80 \%)$ and retail $(100 \%)$ brokers in the minute following the announcement is approximately the same for financial and non-financial firms. That is, at first pass there appears to be little difference between the order submission strategy for financial and non-financial firms.

$<$ Insert Figure 3>

Looking at the order aggressiveness in more detail (Table 6) does indicate some difference. For institutional orders (Panel A), the level of aggressiveness for orders placed in the stocks of financial firms is more aggressive, particularly in the most aggressive (category 1 ) orders. While for retail orders (Panel B), the aggressiveness is actually higher for non-financial stocks. The results are interesting as one might expect order aggressiveness to be concentrated in sectors that have the greatest response to monetary policy news, determined by Ehrmann and Fratzscher (2004) as technology, communication, and cyclical consumer goods rather than financial.

$<$ Insert Table 6>

\subsection{Determinants of Order Aggressiveness}

Having established preliminary evidence of order submission patterns surrounding the announcement of RBA target rate decisions, I seek to empirically examine the determinants of order aggressiveness for institutional and retail brokers over the course of a trading day when an RBA policy announcement is made. In order to do this I utilise an ordered probit model of the

\footnotetext{
${ }^{5}$ Approximately $20 \%$ of the sample is classified as financial.
} 
form suggested by Griffiths et al. (2000), Ranaldo (2004), and Duong et al. (2009). In this model, the dependent variable is the level of order aggressiveness, as classified according to Biasis et al. (1995).

Following Duong et al. (2009), several explanatory variables are used to control for liquidity conditions including the same-side market depth, the opposite-side market depth, the relative bid-ask spread, volatility, order size, and direction of order. The same-side (opposite-side) market depth is defined as the natural logarithm of the same-side (opposite-side) market depth, in terms of the number of shares, at the time of order submission. The relative bid-ask spread is the percentage of the bid-ask spread over the bid-ask mid-point, at the time of order submission. As in Ranaldo (2004), volatility is defined as the standard deviation of the 20 most recent mid-quote returns multiplied by 100 . The order size is the natural logarithm of number of shares in a particular order. Ranaldo (2004) also documents a potential asymmetry of aggression level between buy and sell orders and so I include a dummy variable indicating whether the order is to buy (0) or sell (1).

I augment this specification with three additional variables to explain the influence of the RBA target rate decision. First, given the order submission pattern already identified it is possible that order aggressiveness will differ in the period immediately following the RBA announcement, and so a dummy variable $\left(R B A_{-} 1 M_{k}\right)$ is included to indicate whether the order is submitted in the $1^{\text {st }}$ minute following the announcement $(1)$ or not $(0)$. Second, a variable is included to indicate the ex-ante market expectation of the RBA decision $\left(R B A \_\right.$Expected $k$ ). Third, a variable is included to indicate the surprise component of the RBA announcement (RBA_Surprise $)$ ); this variable is set to 0 prior to the announcement when by definition there can be no surprise. Thus I use the following ordered probit specification in this empirical analysis, with $Z_{k}$ as the latent order aggressiveness:

$$
\begin{aligned}
& Z_{k}=\beta_{1} \text { Depth_Same }_{k}+\beta_{2} \text { Depth_Opp }_{k}+\beta_{3} \text { Spread }_{k}+\beta_{4} \text { Volatility }_{k}+\beta_{5} \text { Order_Size }_{k}+\beta_{6} \text { Sell_Order }_{k} \\
& +\beta_{7} R B A_{-} 1 M_{k}+\beta_{8} R B A_{-} \text {Expected }_{k}+\beta_{9} R B A_{-} \text {Surprise }_{k}+\varepsilon_{k}
\end{aligned}
$$

Table 7 presents the results of my empirical analysis for all orders. For small-cap, mid-cap, and large-cap firms the first column represents the average coefficient of each of the 30 firms within the size category. The second and third column denotes the proportion of firms for which that coefficient was statistically significant (at the $1 \%$ level) and negative or statistically 
significant and positive respectively. Note that more aggressive orders are assigned a lower category number and so a negative (positive) coefficient implies increased (decreased) order aggressiveness as the magnitude of the independent variable increases.

\section{$<$ Insert Table 7>}

The pattern for depth-at-same and depth-at-opposite is similar for both institutional and retail orders; consistent with the extant literature the relationship is negative (positive) for depthat-same (depth-at-opposite) indicating that order aggressiveness increases (decreases) with the number of shares on the same (opposite) side increases. This makes intuitive sense since a larger number of shares on the same (opposite) side reduces (increases) the likelihood of order execution. The magnitude of the coefficient decreases as the firm size falls, and for small firms the coefficient for depth-at-opposite actually becomes negative. One explanation for this may be that for such illiquid, small firms, any increase in liquidity (such as shares on the opposite size of the spread) is seized upon. The relative bid-ask spread has a positive relationship with the order aggressiveness variable, indicating that orders are less aggressive as the spread widens; this is consistent with investors (institutional and retail) not wanting to incur the higher cost of crossing wider spreads. This relationship is strongest for mid-cap stocks.

Consistent with Aitken et al. (2007a), an increase in volatility is associated with more aggressive orders, particularly for retail brokers placing orders in small firms. Foucalt (1999) suggests that higher volatility raises the likelihood of "picking off", and so it may be that this increased order aggression in volatile times is a result of orders attempting to "pick off" limit orders left in the order book. Smales (2012b) highlights the possibility of such "picking off" of stale orders in the period around RBA target rate decisions. For both institutional and retail orders, sell orders are more aggressive for large-cap and mid-cap firms and less aggressive for small-cap firms. One explanation for this is of the higher level of information asymmetry and higher cost of (short-) selling small-cap stocks (Diether et al., 2009). In addition to lower levels of information asymmetry, large cap stocks are also likely to be more intensely monitored and so the accompanying risk of being "picked-off" is also higher.

The main difference between institutional and retail investors appears to be the effect of order size. For retail brokers, the coefficient for order size is generally positive suggesting that larger orders are less aggressive and perhaps indicating that investors using such services are more 
concerned with execution price than with execution speed. For institutional investors the effect of order size is mixed. For mid-cap (small-cap) firms where liquidity is higher (lower) then order size has a negative (positive) relationship in general. However, for large-cap firms whilst order size has a significant impact on 28 (out of 30) firms, the relationship is finely balanced between negative and positive instances.

Considering the variables relevant to the RBA decision, the coefficient for the dummy variable indicating the interval immediately following the announcement is positive for institutional orders (particularly for large-cap firms), and negative for retail orders except in the case of small firms. This result is consistent with the patterns highlighted earlier, such that institutional orders are less aggressive in the period immediately following the announcement, while retail orders are more aggressive. There is no clear relationship between order aggressiveness and market expectations surrounding the RBA decision in the case of institutional brokers with an equal amount of positive and negative coefficients. However, market expectations do seem to play a role in explaining the order aggressiveness of retail brokers; a positive (negative) coefficient for large-cap (mid-cap and small-cap) firms indicating that order aggressiveness decreases (increases) as expectations of tighter monetary policy rise. Finally, there is a significant relationship for the effect of the RBA target rate surprise across institutional and retail orders, and this is particularly strong for small-cap firms. The positive coefficient indicates that order aggressiveness increases (decreases) as the RBA surprises with easier (tighter) policy. The extant literature reports that market returns are more volatile in response to surprise easing, and so this result is consistent with the finding that orders are more aggressive when volatility is highest.

I investigate the asymmetry of buy and sell orders identified in Ranaldo (2004) by disaggregating the orders into those placed on the bid side, and those placed on the ask side, and then repeating my analysis. Table 8 presents the results for the buy and sell orders submissions disaggregated by both institutional and retail brokers. Panel A and Panel B relates to institutional brokers. In general, the results are qualitatively similar to those already identified. However, market expectations concerning the RBA decision play an important role in this disaggregated model, with a positive (negative) relationship for buy (sell) orders indicating that as expectations of tighter policy increase then buy (sell) orders are less (more) aggressive. Since tighter (easier) monetary policy is consistent with stock prices falling (rising) this result is consistent with institutional brokers been less (more) willing to buy (sell) stocks. 
$<$ Insert Table 8>

Panel C and Panel D report the results for the determinants of buy and sell orders submitted by retail brokers. Again, the relationships are broadly similar to those for the aggregated orders, although the importance of market expectations pertaining to the policy decision is emphasised once more, with a significant and positive (negative) relationship for buy (sell) orders. In addition, the effect of the order being submitted in the immediate aftermath of the announcement appears to be dependent on whether the order is to buy or sell. Buy orders from retail brokers appear to be less aggressive in the minute following the RBA announcement; this is consistent with institutional orders. On the other hand, retail sell orders tend to be more aggressive following the decision.

\section{Inferences from empirical results}

Consistent with the extant literature ${ }^{6}$ on the market impact of macroeconomic announcements in general, and monetary policy news in particular, there is a sharp increase in market activity in the period immediately following RBA announcements. The scale of this reaction is dependent on both the magnitude and direction of the surprise component of the target rate decision. Orders are more prevalent, and more aggressive, when information asymmetry is lowest and there is a lesser quantity of information to absorb before entering an order into the market; this most commonly occurs when market expectations of the RBA leaving rates on hold come to fruition. This is also consistent with the finding that orders are more aggressive on days without RBA target rate announcements. Conversely, orders are less ubiquitous, and less aggressive, when the market is surprised by easier monetary policy.

On average, retail orders are more aggressive than those placed by institutions and this difference is polarized further in the period that follows RBA rate decisions as institutional brokers make greater use of the least aggressive orders. In this interval, retail brokers are demanding a higher amount of liquidity that is then provided by institutional brokers. If I assume that institutional orders are more informed, in the sense that they can more readily interpret the policy decision, then this evolving liquidity provision is consistent with the experimental results of Bloomfield et al. (2005). An alternative way of considering this dynamic process, consistent

\footnotetext{
${ }^{6}$ For example, Ederington and Lee (1993,1995), Fargher and Weigand (1998), Fatum and Scholnick (2008), and Smales (2013)
} 
with Foucalt (1999), is that institutional brokers are more wary about been "picked-off" in fastmoving markets, with increased levels of information asymmetry, and so make greater use of limit orders, while retail investors are more concerned about expediency of trade execution. This fear of being "picked-off" is also evident in the negative relationship between volatility and order aggression. Such evidence also fits with the "value-motivated traders" identified by Harris (1998) who demand immediacy when they believe the stock is mis-valued (immediately after the announcement) and otherwise set limit orders to profit from pricing errors that may arise.

It is possible to test which of these alternatives is most likely to be correct by performing a simple experiment. I focus on trades ${ }^{7}$ that occur in the period immediately following RBA announcements, and consider the price impact (in terms of absolute returns following trade initiation) of those trades that occur between two groups. Group 1 are trades initiated by retail brokers with an institutional broker as counterparty. Group 2 has trades initiated by retail brokers with non-institutional counterparties. If the price impact of trades in group 1 is lower than those of group 2, then it is likely that institutional investors are engaging in informed limit order trading. Table 9 presents evidence to this effect. The price impact is lower in group 1 and so it appears institutional investors are indeed more informed than retail investors, and this is particularly true in the case of large-cap stocks.

\section{$<$ Insert Table 9>}

Disaggregating orders into buy and sell types reveals further evidence that order aggression is related to the market expectations and interpretation of the RBA target rate decisions; with institutional brokers less (more) willing to buy (sell) shares ahead of rate hikes (cuts) which are associated with stock price falls (increases).

A combination of the likelihood and the cost of order execution plays an important role in determining the aggressiveness of orders placed by both institutional and retail brokers. Factors that improve the likelihood of the order being executed (lower depth-at-same, higher depth-atopposite) and factors that increase the cost of execution (higher bid-ask spreads) serve to reduce order aggressiveness. Liquidity concerns appear to play a role in the divergent order aggressiveness patterns identified for institutional orders in firms of different sizes. For large-cap

\footnotetext{
${ }^{7} \mathrm{NB}$ : This experiment relates to trades rather than order submission focused on in the remainder of the paper.
} 
stocks, order aggression is lower prior to the decision, rises as the decision is announced, and then subsides; the reverse is found for small-cap and mid-cap stocks. Such results align with the work of Ranaldo (2004) and Duong et al. (2009)

\section{Conclusion}

This paper examines the pattern of order aggressiveness, and the determinants of this pattern, for institutional and retail brokers in the interval around RBA monetary policy announcements. I identify a sharp increase in the number of orders submitted to the order book following the announcement. Apparently, orders are more numerous, and more aggressive, when there is less information for investors to digest. On average, retail orders are more aggressive and are exclusively concerned with the likelihood of order execution. The submission decision of institutional brokers is more nuanced and evolves over time as market conditions change and information arrives. Differences in order aggressiveness are recognized on the basis of firm-size and industry.

The study fills an important gap in the literature concerning the order submission process by considering the influence of important news events on the choice of aggressiveness level. The results add to the discussion on market efficiency and liquidity provision at times of intense market activity. This provides greater cognizance to investors seeking to minimise trading costs, and maximise returns, in the optimization of their trading decisions. The results are also important for central banks in understanding the impact of their announcements on market liquidity and asset prices, and policy makers in determining exchange rules.

Further research in this area may consider whether different broker-types have an informational advantage in terms of the subsequent performance of their executed trades. It may also be possible to incorporate a broader range of macroeconomic announcements in order to test the generalizability of the results. Finally, practitioners and policy makers are likely to be interested in more explicit measurements of trading costs and execution likelihood during the period surrounding monetary policy announcements. 


\section{References}

Aitken, M., N. Almeida, F.H.deB. Harris, and T.H. McInish, 2007a, Liquidity supply in electronic markets, Journal of Financial Markets, 10, 144-168

Aitken, M., P. Brown, and M. Wee, 2007b, Institutional versus retail traders: a comparison of their order placement strategies, Working Paper, University of Western Australia

Bernanke, B.S. and K.N. Kuttner, 2005, What explains the stock market's reaction to Federal Reserve policy? Journal of Finance, 60, 1221-1257

Bessembinder, H., K. Chan, and P.J. Seguin, 1996, An empirical explanation of information, differences of opinion, and trading activity, Journal of Financial Economics, 30, 105-134

Biais, B., P. Hillion, and C. Spatt, 1995, An empirical analysis of the limit order book and the order flow in the Paris Bourse, Journal of Finance, 50, 1655-1689

Bloomfield, R., M. O'Hara, and G. Saar, 2005, The "make or take" decision in an electronic market: Evidence on the evolution of liquidity, Journal of Financial Economics, 75, 165-200

Chae, J., 2005, Trading volume, information asymmetry, and timing information, Journal of Finance, 60, 413-442

Cook, T., and T. Hahn, 1989, The effect of changes in the federal funds rate target on market interest rates in the 1970s, Journal of Monetary Economics, 24, 331-351

Diether, K.B., K.-H. Lee, I.M. Werner, 2009, Short-sale strategies and return predictability, Review of Financial Studies, 22, 575-607

Duong, H.N., P.S. Kalev, and C. Krishnamurti, 2009, Order aggressiveness of institutional and individual investors, Pacific Basin Finance Journal, 17, 533-546

Ederington, L., and J. Lee, 1993, How markets process information: News releases and volatility, Journal of Finance, 48, 1161-1191

Ederington, L., and J. Lee, 1995, The short-run dynamics of the price adjustment to new information, Journal of Financial and Quantitative Analysis, 30, 117-134

Ehrmann, M., and M. Fratzscher, 2004, Taking stock: Monetary policy transmission to equity markets, Journal of Money, Credit and Banking, 36, 719-737

Erenburg, G., A. Kurov, and D.J. Lasser, 2006, Trading around macroeconomic announcements: Are all traders created equal? Journal of Financial Intermediation, 15, 470-493

Fargher, N., and R. Weigand, 1998, Changes in the stock price reaction of small firms to common information, Journal of Financial Research, 21, 105-121

Fatum, R., and B. Scholnick, 2008, Monetary policy news and exchange rates: Do only surprises matter? Journal of Banking and Finance, 32, 1076-1086 
Fleming, M.J., and M. Piazzesi, 2005, Monetary policy tick-by-tick, Working paper Federal Reserve Bank of New York

Fleming, M.J., and E.M. Remolona, 1999, Price formation and liquidity in the U.S. treasury market: The response to public information, Journal of Finance, 54, 1901-1915

Fong, K.Y.L., D.R. Gallagher, and A.D. Lee, 2014, Individual investors and broker types, Journal of Financial and Quantitative Analysis, 49, 431-451

Foucalt, T., 1999, Order flow composition and trading costs in a dynamic limit order market, Journal of Financial Markets, 2, 99-134

Frino, A., and A. Hill, 2001, Intraday futures market behavior around scheduled macroeconomic announcements: Australian evidence, Journal of Banking and Finance, 25, 1319-1337

Griffiths, M.D., B. Smith, D.A.S. Turnbull, and R.W. White, 2000, The costs and determinants of order aggressiveness, Journal of Financial Economics, 56, 65-88

Gurkaynak, R. S., B. Sack, and E. Swanson, 2005, Do actions speak louder than words? The response of asset prices to monetary policy actions and statements, International Journal of Central Banking, 1, 55-93

Hall, A.D., and N. Hautsch, 2006, Order aggressiveness and order book dynamics, Empirical Economics, 30, 973-1005

Handa, P., Schwartz, R., Tiwari, A., 2003. Quote setting and price formation in an order driven market. Journal of Financial Markets, 6, 461-489.

Harris, L., 1998, Optimal dynamic order submission strategies in some stylized trading problems, Financial Markets, Institutions and Instruments, 7, 1-75

He, W.P., and A. Lepone, 2014, Determinants of liquidity and execution probability in exchange operated dark pool: Evidence from the Australian Securities Exchange, Pacific Basin Finance Journal, 30, 1-16

Kandel, E., and N.D. Pearson, 1995, Differential interpretation of public signals and trade in speculative markets, Journal of Political Economy, 103, 831-872

Kuttner, K., 2001, Monetary policy surprises and interest rates: Evidence from the Fed funds futures market, Journal of Monetary Economics, 47, 523-544

Lebedeva, O., 2014, Trading aggressiveness and its implications for market efficiency, Working Paper Warwick Business School

Lo, I., and S.G. Sapp, 2010, Order aggressiveness and quantity: How are they determined in a limit order market? Journal of International Financial Markets, Institutions and Money, 20, 213-237

Nofsinger, J.R., 2001, The impact of public information on investors, Journal of Banking and Finance, 25, $1339-1366$

Parlour, C., 1998. Price dynamics in limit order markets, Review of Financial Studies, 11, 789-816

Ranaldo, A., 2004, Order aggressiveness in limit order book markets, Journal of Financial Markets, 7, 53-74 
Ruhl, T.R., and M. Stein, 2015, The impact of ECB macro announcements on bid-ask spreads of European blue chips, Journal of Empirical Finance, Forthcoming

Sakar, A., and R.A. Schwartz, 2009, Market sidedness: Insights into motives for trade initiation, Journal of Finance, 64, 375-423

Smales, L.A., 2012a, RBA monetary policy communication: The response of Australian interest rate futures to changes in RBA monetary policy, Pacific Basin Finance Journal, 20, 793-808

Smales, L.A., 2012b, 30-day interbank futures: Investigating the process of price discovery following RBA cash target rate announcements, Journal of International Financial Markets, Institutions and Money, 22, 1006-1023

Smales, L.A., 2013, Impact of macroeconomic announcements on interest rate futures: High-frequency evidence from Australia, Journal of Financial Research, 36, 371-388

\section{Appendix A}

The order book data provides a broker identity number for each order that is submitted. This number is matched with a broker name from a list provided directly from SIRCA. I then classify each broker into one of five distinct categories: retail, institutional, mixed (retail and institutional), market-maker, and other. Six broker numbers do not have a match in the name-list and so as classified as "other". The steps I take to assign the broker classification are as follows:

i. Check broker's existing or archived website.

ii. If no website exists or the broker-type cannot be determined, search Factiva for newspaper articles, trade journals, company announcements, or web articles on the broker.

iii. If no Factiva articles exist to classify the broker, use a Google search for any credible articles that may classify the broker.

iv. If the broker still exists today but has no identifying information from any of the sources in the first 3 steps, I telephone the broker and ask for their targeted clientele and services.

v. If a broker's classification cannot be determined from steps 1-4, the broker is classified as 'Other'. 


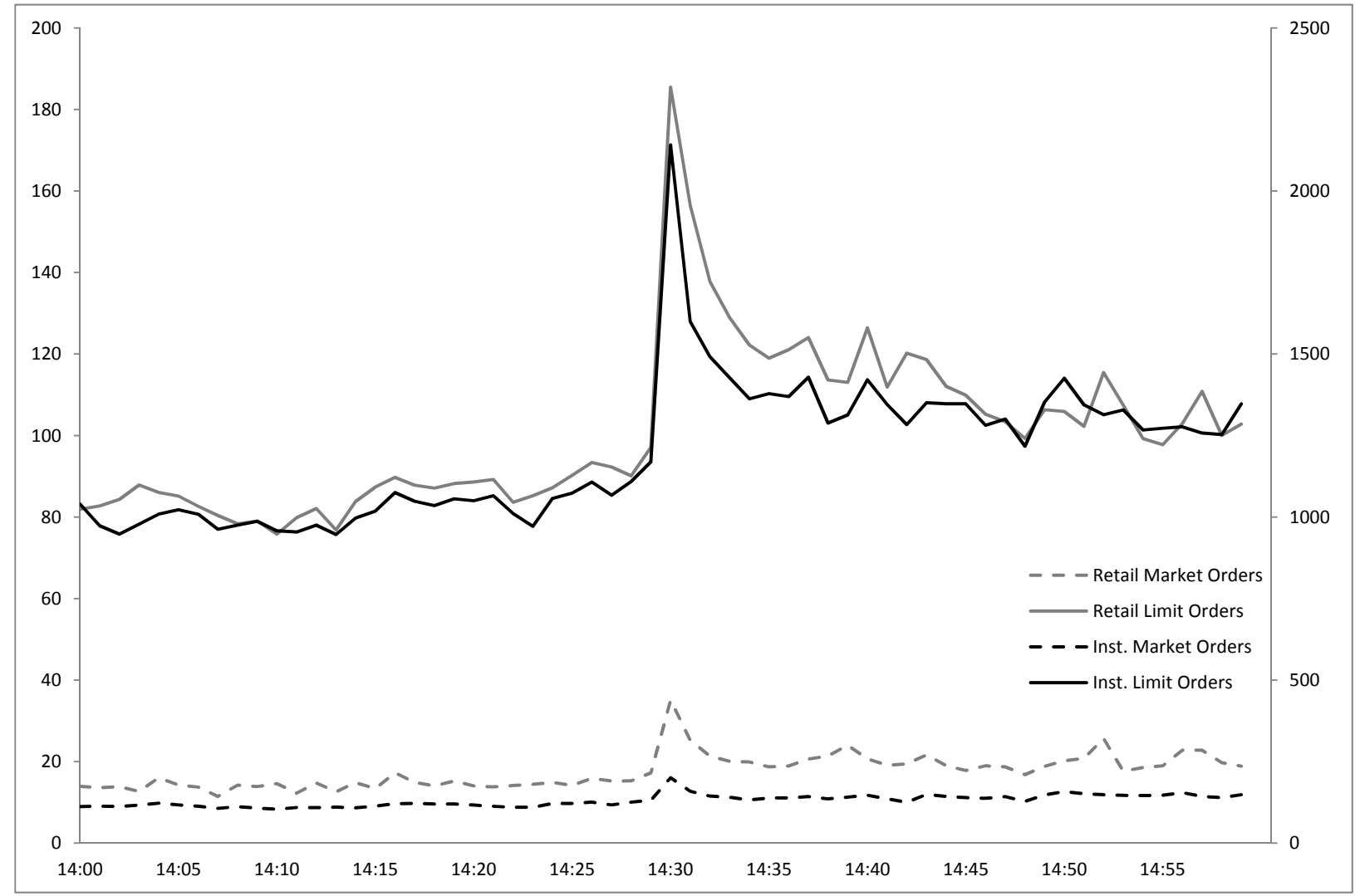

Figure 1: Number of orders placed by institutional and retail brokers around RBA target rate announcement

This figure depicts the number of orders submitted by institutional and retail brokers in the 1-hour period (-30min, $+30 \mathrm{~min})$ around the 14:30 (AEST) RBA target rate announcement. Orders of aggressiveness in categories 1, 2, and 3 are grouped as market orders. Orders with aggressiveness levels 4, 5, and 6 are grouped as limit orders. The number of retail orders is shown on the left-hand scale, the (larger) number of institutional orders is displayed on the right-hand scale. Sample includes RBA announcements in the period December 2007 - December 2014. 

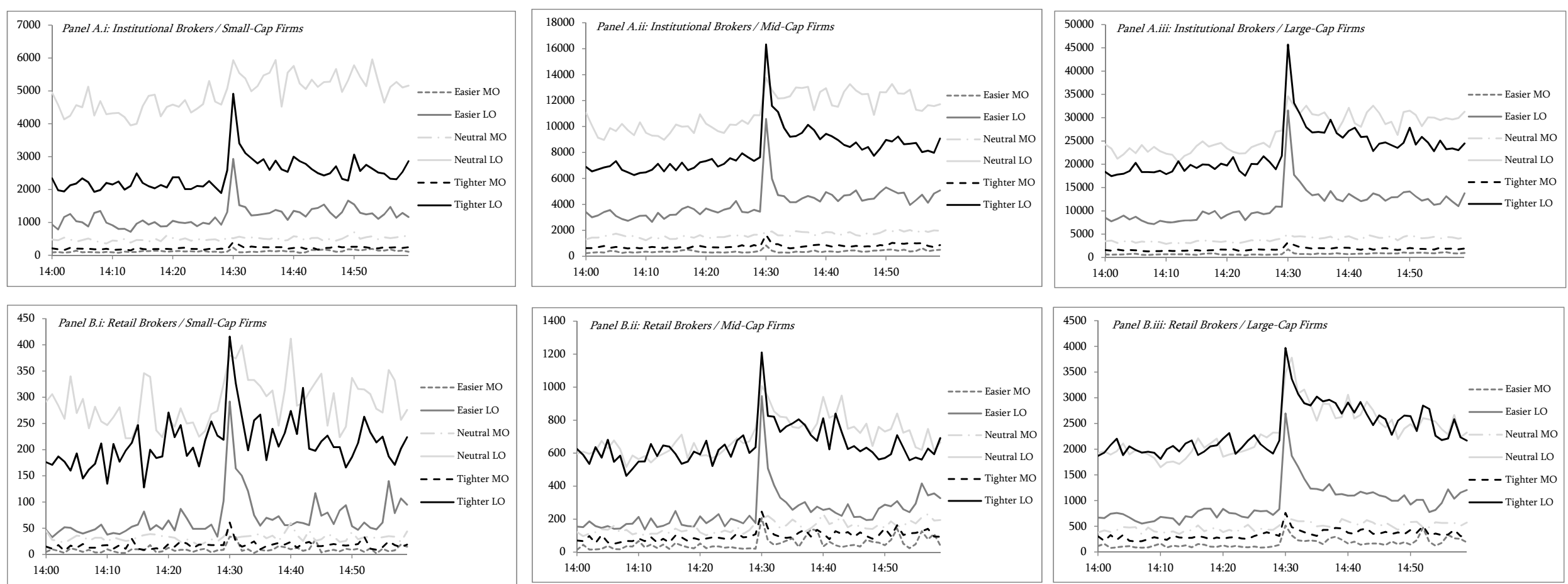

Figure 2: Number of orders placed by institutional and retail brokers as a result of RBA target rate surprises

This chart depicts the number of orders submitted by institutional (Panel A) and retail (Panel B) brokers in the 1-hour period (-30min, $+30 \mathrm{~min}$ ) around the 14:30 (AEST) RBA target rate announcement. Panels $x . i, x . i i$, and $x . i i i$ illustrate patterns for small-cap, mid-cap, and large-cap firms respectively. $M O$ refers to market orders (categories 1, 2,3) and $L O$ refers to limit orders (categories 4, 5, 6). Easier refers to RBA target rate decisions that surprise the market with easier than expected policy. Tighter refers to RBA decisions that surprise with tighter than expected policy. Neutral refers to RBA decisions that are in-line (within 1 b.p.) with market expectations. Sample includes RBA announcements in the period December 2007 - December 2014. 

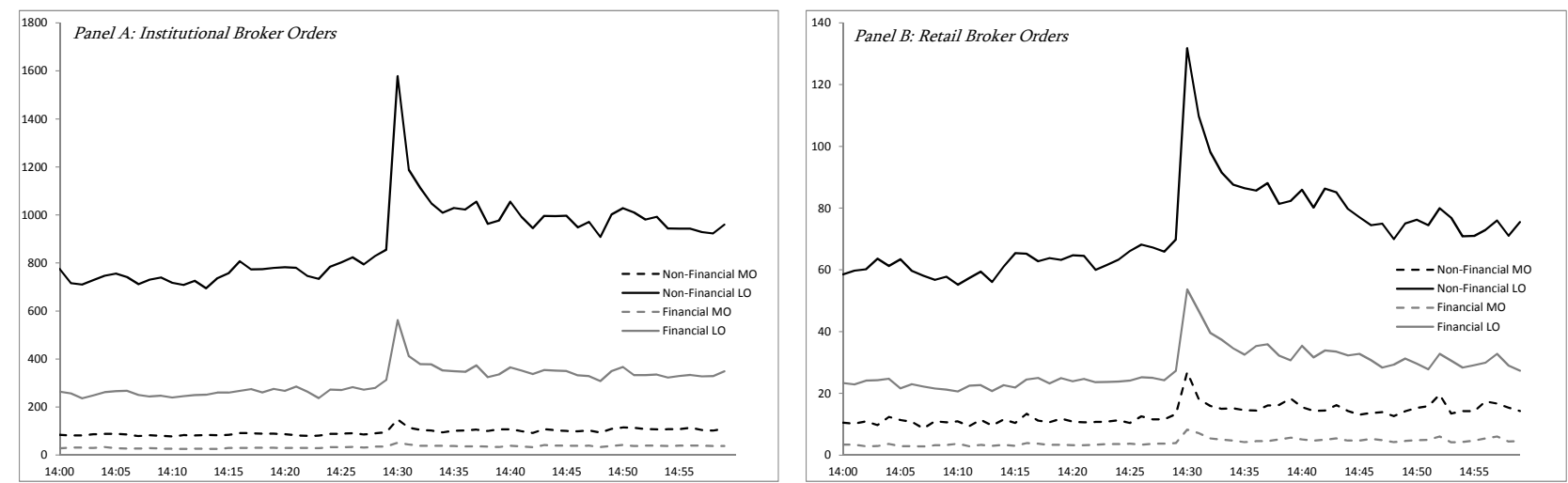

Figure 3: Number of orders placed by institutional and retail brokers in financial and non-financial firms around RBA target rate announcement

This figure depicts the number of orders submitted by institutional and retail brokers in the 1-hour period $(-30 \mathrm{~min},+30 \mathrm{~min}$ ) around the 14:30 (AEST) RBA target rate announcement. Firms are classified as Financial or non-Financial according to their 2-digit GICS sector code. Orders of aggressiveness in categories 1, 2, and 3 are grouped as market orders. Orders with aggressiveness levels 4, 5, and 6 are grouped as limit orders. Panel A displays orders placed through institutional brokers, and panel B displays retail broker orders. Sample includes RBA announcements in the period December 2007 - December 2014. 
Table 1

Descriptive Statistics

Panel A: Stocks

\begin{tabular}{lrrrrrr}
\hline \multicolumn{1}{c}{ Firm Size } & \multicolumn{1}{c}{ Turnover } & Share Volume & Trade Volume & Relative Spread & Return & Mkt Cap (\$MM) \\
\hline Large-Cap & $87,273,538$ & $7,546,618$ & 6,121 & 0.045 & 0.046 & $25,477.4$ \\
Mid-Cap & $11,794,780$ & $2,482,646$ & 2,657 & $0.122-$ & 0.024 & $2,721.1$ \\
Small-Cap & $2,578,828$ & 618,588 & 1,002 & $0.160-$ & 0.016 & 902.2 \\
Most Traded (BHP) & $416,548,562$ & $11,196,875$ & 15,368 & $0.004-$ & 0.038 & $122,064.4$ \\
Least Traded (VRL) & 535,409 & 117,741 & 281 & 0.631 & 0.160 & 546.0 \\
\hline
\end{tabular}

Panel B: Order Submission

\begin{tabular}{|c|c|c|c|c|c|c|c|c|}
\hline Aggressiveness Level & Frequency & $\%$ of all orders & Order Size & Order Value & Relative spread & Volatility & Depth at same & Depth at opposite \\
\hline \multicolumn{9}{|l|}{ Institutional Orders } \\
\hline 1 & 17,934 & $3.91 \%$ & 1,576 & 22,530 & 0.119 & 0.109 & 28,532 & 151,075 \\
\hline 2 & 4,404 & $0.96 \%$ & 7,617 & 52,855 & 0.091 & 0.081 & 20,563 & 123,689 \\
\hline 3 & 25,645 & $5.59 \%$ & 1,580 & 15,254 & 0.163 & 0.054 & 103,881 & 474,283 \\
\hline 4 & 5,130 & $1.12 \%$ & 2,318 & 20,762 & 0.184 & 0.118 & 5,884 & 36,276 \\
\hline 5 & 196,300 & $42.83 \%$ & 2,622 & 31,021 & 0.174 & 0.062 & 85,021 & 435,854 \\
\hline 6 & 208,960 & $45.59 \%$ & 1,647 & 21,044 & 0.097 & 0.081 & 34,525 & 186,086 \\
\hline \multicolumn{9}{|l|}{ Retail Orders } \\
\hline 1 & 2,892 & $6.91 \%$ & 1,576 & 18,814 & 0.731 & 0.109 & 41,878 & 228,257 \\
\hline 2 & 827 & $1.97 \%$ & 5,143 & 65,677 & 0.032 & 0.096 & 13,997 & 81,925 \\
\hline 3 & 2,725 & $6.51 \%$ & 2,252 & 8,348 & 0.152 & 0.070 & 148,377 & 712,202 \\
\hline 4 & 1,126 & $2.69 \%$ & 1,291 & 35,504 & 0.196 & 0.121 & 4,764 & 28,039 \\
\hline 5 & 12,892 & $30.78 \%$ & 2,750 & 15,532 & 0.159 & 0.072 & 76,247 & 357,624 \\
\hline 6 & 21,417 & $51.14 \%$ & 1,905 & 15,027 & 0.082 & 0.082 & 41,143 & 210,415 \\
\hline
\end{tabular}

This table provides descriptive statistics for the stocks and order submission of institutional and retail brokers used in this study. Panel A provides summary statistics for stocks classified as large-cap (S\&P/ASX50), mid-cap (S\&P/ASX100 but not S\&P/ASX50) and small-cap (S\&P/ASX200 but not S\&P/ASX100). In addition, statistics are provided for the most traded stock in the sample (BHP) and the least traded stock (VRL). Turnover is the average value of shares traded on a daily basis, share volume is the average number of shares traded on a daily basis, trade volume is the daily average number of trades, relative spread is the percentage of the percentage of the bid-ask spread over the bid-ask midpoint, return is the average daily percentage return, and market capitalisation is the average market capitalisation over the course of the sample period. In each case, the reported value is for the average stock within the particular firm size category. Panel B reports statistics for order submission where orders are classified according to the six aggressiveness levels of Biais et al. (1995). Category 1 orders are buy (sell) orders with prices greater (less) than the best ask (bid) quote and order size exceeding the market depth at the best ask (bid) quote, and are the most aggressive. Category 2 orders are buy (sell) orders with prices equal to the best ask (bid) quote and demand more volume than the market depth at the best ask (bid). Category 3 orders are orders with the price equal to the opposite best quote and demand less volume than the market depth at the opposite best quote. Category 4 and Category 5 orders are limit orders within and at the prevailing quotes. Category 6 orders are buy (sell) orders with prices less (greater) than the best bid (ask) quotes and are the least aggressive. Frequency is the average number of orders submitted at that aggressiveness level on an average trading day containing an RBA target rate decision. Order size is the average number of share submitted in an order and order value is the value of those shares. Relative spread is calculated as the percentage of the bid-ask spread over the bid-ask mid-point. Volatility is the average volatility at the time of a submitted order at that level, calculated as the standard deviation of the most recent 20 mid-quote returns at the time of the order submission multiplied by 100. Depth-at-same is the average number of shares at the 10 best same-side quotes at the time of order submission. Depth-at-opposite is the average number of shares at the 10 best opposire-side quotes at the time of order submission. The reported orders submissions are the average occuring during the whole trading day of an RBA announcement.

The sample period includes the RBA announcement days that occur during the period 05 December 2007 - 02 December 2014 
Table 2

The pattern of order aggressiveness in the period surrounding RBA target rate announcements

\begin{tabular}{|c|c|c|c|c|c|c|c|c|c|}
\hline \multirow{2}{*}{ Interval } & \multicolumn{6}{|c|}{ Order Aggressiveness Level } & \multirow{2}{*}{$\mathrm{MO}$} & \multirow{2}{*}{ LO } & \multirow{2}{*}{ Orders in Interval } \\
\hline & 1 & 2 & 3 & 4 & 5 & 6 & & & \\
\hline \multicolumn{10}{|c|}{ Panel A: Institutional Orders } \\
\hline $14: 25-14: 26$ & 0.035 & 0.010 & 0.057 & 0.010 & 0.435 & 0.453 & 0.102 & 0.898 & 1195 \\
\hline $14: 26-14: 27$ & 0.038 & 0.009 & 0.056 & 0.008 & 0.427 & 0.462 & 0.102 & 0.898 & 1234 \\
\hline $14: 27-14: 28$ & 0.036 & 0.009 & 0.054 & 0.009 & 0.424 & 0.468 & 0.099 & 0.901 & 1185 \\
\hline $14: 28-14: 29$ & 0.036 & 0.009 & 0.057 & 0.009 & 0.427 & 0.462 & 0.102 & 0.898 & 1236 \\
\hline $14: 29-14: 30$ & 0.038 & 0.009 & 0.054 & 0.010 & 0.418 & 0.472 & 0.101 & 0.899 & 1301 \\
\hline $14: 30-14: 31$ & 0.028 & 0.010 & 0.048 & 0.014 & 0.401 & 0.499 & 0.086 & 0.914 & 2342 \\
\hline $14: 31-14: 32$ & 0.034 & 0.010 & 0.047 & 0.015 & 0.413 & 0.481 & 0.091 & 0.909 & 1759 \\
\hline $14: 32-14: 33$ & 0.037 & 0.010 & 0.041 & 0.013 & 0.412 & 0.486 & 0.088 & 0.912 & 1637 \\
\hline $14: 33-14: 34$ & 0.036 & 0.010 & 0.044 & 0.014 & 0.414 & 0.482 & 0.090 & 0.910 & 1568 \\
\hline $14: 34-14: 35$ & 0.036 & 0.009 & 0.044 & 0.011 & 0.420 & 0.480 & 0.089 & 0.911 & 1496 \\
\hline $14: 35-14: 36$ & 0.035 & 0.009 & 0.047 & 0.012 & 0.422 & 0.475 & 0.091 & 0.909 & 1518 \\
\hline $14: 36-14: 37$ & 0.035 & 0.009 & 0.048 & 0.010 & 0.426 & 0.471 & 0.092 & 0.908 & 1509 \\
\hline $14: 37-14: 38$ & 0.037 & 0.009 & 0.045 & 0.011 & 0.420 & 0.478 & 0.091 & 0.909 & 1572 \\
\hline $14: 38-14: 39$ & 0.034 & 0.010 & 0.051 & 0.012 & 0.420 & 0.472 & 0.095 & 0.905 & 1424 \\
\hline $14: 39-14: 40$ & 0.040 & 0.009 & 0.048 & 0.010 & 0.421 & 0.472 & 0.097 & 0.903 & 1455 \\
\hline \multicolumn{10}{|c|}{ Panel B: Retail Orders } \\
\hline $14: 25-14: 26$ & 0.058 & 0.017 & 0.061 & 0.019 & 0.327 & 0.517 & 0.136 & 0.864 & 104 \\
\hline $14: 26-14: 27$ & 0.065 & 0.017 & 0.064 & 0.018 & 0.312 & 0.524 & 0.146 & 0.854 & 109 \\
\hline $14: 27-14: 28$ & 0.068 & 0.015 & 0.058 & 0.020 & 0.337 & 0.502 & 0.142 & 0.858 & 108 \\
\hline $14: 28-14: 29$ & 0.060 & 0.018 & 0.067 & 0.018 & 0.332 & 0.504 & 0.145 & 0.855 & 105 \\
\hline $14: 29-14: 30$ & 0.056 & 0.022 & 0.073 & 0.020 & 0.311 & 0.518 & 0.151 & 0.849 & 114 \\
\hline $14: 30-14: 31$ & 0.070 & 0.022 & 0.067 & 0.049 & 0.321 & 0.471 & 0.159 & 0.841 & 221 \\
\hline $14: 31-14: 32$ & 0.058 & 0.022 & 0.059 & 0.048 & 0.338 & 0.474 & 0.139 & 0.861 & 182 \\
\hline $14: 32-14: 33$ & 0.059 & 0.021 & 0.055 & 0.030 & 0.343 & 0.492 & 0.134 & 0.866 & 159 \\
\hline $14: 33-14: 34$ & 0.063 & 0.019 & 0.053 & 0.036 & 0.337 & 0.492 & 0.135 & 0.865 & 149 \\
\hline $14: 34-14: 35$ & 0.057 & 0.019 & 0.063 & 0.030 & 0.345 & 0.485 & 0.140 & 0.860 & 142 \\
\hline $14: 35-14: 36$ & 0.063 & 0.020 & 0.053 & 0.024 & 0.352 & 0.487 & 0.136 & 0.864 & 138 \\
\hline $14: 36-14: 37$ & 0.052 & 0.021 & 0.063 & 0.040 & 0.375 & 0.450 & 0.135 & 0.865 & 140 \\
\hline $14: 37-14: 38$ & 0.063 & 0.019 & 0.061 & 0.026 & 0.361 & 0.470 & 0.143 & 0.857 & 145 \\
\hline $14: 38-14: 39$ & 0.064 & 0.019 & 0.064 & 0.027 & 0.375 & 0.452 & 0.147 & 0.853 & 135 \\
\hline $14: 39-14: 40$ & 0.065 & 0.019 & 0.062 & 0.029 & 0.367 & 0.458 & 0.146 & 0.854 & 137 \\
\hline
\end{tabular}

This table presents information on the pattern of order aggressiveness in the period surrounding the RBA target rate decision at 14:30 (AEST). The period runs from 5-minutes prior to the announcement to 10-minutes after the announcement. Orders are classified according to the six aggressiveness levels of Biais et al. (1995). Category 1 orders are buy (sell) orders with prices greater (less) than the best ask (bid) quote and order size exceeding the market depth at the best ask (bid) quote, and are the most aggressive. Category 2 orders are buy (sell) orders with prices equal to the best ask (bid) quote and demand more volume than the market depth at the best ask (bid). Category 3 orders are orders with the price equal to the opposite best quote and demand less volume than the market depth at the opposite best quote. Category 4 and Category 5 orders are limit orders within and at the prevailing quotes. Category 6 orders are buy (sell) orders with prices less (greater) than the best bid (ask) quotes and are the least aggressive. The numbers reported are the proportion of orders falling within each category in the given interval. $M O$ is the proportion of market orders consisting of order aggression levels 1, 2, and 3. $L O$ is the proportion of limit orders consisting of order aggression levels 4 , 5, and 6. Orders in interval provides an indication of the average number of all orders posted in that particular interval on the day of an RBA target rate decision.

The sample period includes the RBA announcement days that occur during the period 05 December 2007 - 02 December 
Table 3

The pattern of order aggressiveness on days without RBA target rate announcements

\begin{tabular}{|c|c|c|c|c|c|c|c|c|c|c|c|c|c|c|c|c|c|}
\hline \multirow{2}{*}{$\begin{array}{l}\text { Panel A: } \\
\text { Institutional Orders } \\
\quad \text { Interval }\end{array}$} & \multicolumn{6}{|c|}{ Order Aggressiveness Level } & \multirow{2}{*}{ MO } & \multirow{2}{*}{ LO } & \multirow{2}{*}{$\begin{array}{l}\text { Panel B: } \\
\text { Retail Orders } \\
\quad \text { Interval }\end{array}$} & \multicolumn{6}{|c|}{ Order Aggressiveness Level } & \multirow{2}{*}{ MO } & \multirow{2}{*}{ LO } \\
\hline & 1 & 2 & 3 & 4 & 5 & 6 & & & & 1 & 2 & 3 & 4 & 5 & 6 & & \\
\hline All Firms & & & & & & & & & All Firms & & & & & & & & \\
\hline $14: 28-14: 29$ & 0.022 & 0.085 & 0.136 & 0.008 & 0.363 & 0.386 & 0.243 & 0.757 & $14: 28-14: 29$ & 0.071 & 0.082 & 0.177 & 0.025 & 0.272 & 0.373 & 0.329 & 0.670 \\
\hline $14: 29-14: 30$ & 0.021 & 0.092 & 0.129 & 0.018 & 0.346 & 0.394 & 0.242 & 0.758 & $14: 29-14: 30$ & 0.063 & 0.080 & 0.176 & 0.027 & 0.256 & 0.395 & 0.319 & 0.678 \\
\hline $14: 30-14: 31$ & 0.029 & 0.082 & 0.144 & 0.012 & 0.324 & 0.409 & 0.255 & 0.745 & $14: 30-14: 31$ & 0.068 & 0.073 & 0.155 & 0.051 & 0.268 & 0.383 & 0.296 & 0.702 \\
\hline $14: 31-14: 32$ & 0.028 & 0.090 & 0.126 & 0.022 & 0.337 & 0.397 & 0.244 & 0.756 & 14:31-14:32 & 0.067 & 0.082 & 0.166 & 0.049 & 0.275 & 0.364 & 0.316 & 0.688 \\
\hline $14: 32-14: 33$ & 0.028 & 0.100 & 0.112 & 0.011 & 0.349 & 0.400 & 0.240 & 0.760 & $14: 32-14: 33$ & 0.072 & 0.080 & 0.155 & 0.034 & 0.287 & 0.366 & 0.307 & 0.688 \\
\hline $14: 33-14: 34$ & 0.027 & 0.098 & 0.121 & 0.016 & 0.341 & 0.397 & 0.245 & 0.755 & $14: 33-14: 34$ & 0.075 & 0.076 & 0.145 & 0.039 & 0.283 & 0.378 & 0.296 & 0.700 \\
\hline $14: 34-14: 35$ & 0.026 & 0.108 & 0.129 & 0.009 & 0.332 & 0.395 & 0.263 & 0.737 & $14: 34-14: 35$ & 0.065 & 0.074 & 0.164 & 0.034 & 0.281 & 0.377 & 0.303 & 0.692 \\
\hline
\end{tabular}

This table presents information on the pattern of order aggressiveness, in the period surrounding the RBA target rate decision at 14:30 (AEST). The period runs from 2-minutes prior to the announcement to 5-minutes after the announcement. Orders are classified according to the six aggressiveness levels of Biais et al. (1995). Category 1 orders are buy (sell) orders with prices greater (less) than the best ask (bid) quote and order size exceeding the market depth at the best ask (bid) quote, and are the most aggressive. Category 2 orders are buy (sell) orders with prices equal to the best ask (bid) quote and demand more volume than the market depth at the best ask (bid). Category 3 orders are orders with the price equal to the opposite best quote and demand less volume than the market depth at the opposite best quote. Category 4 and Category 5 orders are limit orders within and at the prevailing quotes. Category 6 orders are buy (sell) orders with prices less (greater) than the best bid (ask) quotes and are the least aggressive. The numbers reported are the proportion of orders falling within each category in the given interval. $M O$ the proportion of market orders consisting of order aggression levels 1, 2, and 3. LO is the proportion of limit orders consisting of order aggression levels 4,5 , and 6. A random sample of 100 (Tuesday) trading days that do not include a RBA announcement are included in the analysis

Sample period 05 December 2007 - 02 December 2014 
Table 4

Who is the counterparty on RBA announcement day?

\begin{tabular}{|c|c|c|c|c|c|}
\hline & Countparty & \% Trades & & Countparty & $\%$ Trades \\
\hline \multicolumn{6}{|c|}{ Panel $A:$ All trades on $R B A$ announcement day } \\
\hline \multirow{3}{*}{ All Retail } & Retail & $7.8 \%$ & \multirow{3}{*}{ Retail Initiated } & Retail & $6.1 \%$ \\
\hline & Institutional & $83.3 \%$ & & Institutional & $86.5 \%$ \\
\hline & Other & $8.9 \%$ & & Other & $7.4 \%$ \\
\hline \multirow{3}{*}{ All Institutional } & Retail & $13.6 \%$ & \multirow{3}{*}{ Institutional Initiated } & Retail & $8.8 \%$ \\
\hline & Institutional & $85.3 \%$ & & Institutional & $83.5 \%$ \\
\hline & Other & $1.2 \%$ & & Other & $7.8 \%$ \\
\hline \multicolumn{6}{|c|}{ Panel B: Trades occuring in the 5-minutes post-RBA announcement } \\
\hline \multirow{3}{*}{ All Retail } & Retail & $7.6 \%$ & \multirow{3}{*}{ Retail Initiated } & Retail & $6.4 \%$ \\
\hline & Institutional & $82.9 \%$ & & Institutional & $85.4 \%$ \\
\hline & Other & $9.5 \%$ & & Other & $8.2 \%$ \\
\hline \multirow{3}{*}{ All Institutional } & Retail & $11.7 \%$ & \multirow{3}{*}{ Institutional Initiated } & Retail & $9.2 \%$ \\
\hline & Institutional & $77.5 \%$ & & Institutional & $82.5 \%$ \\
\hline & Other & $10.8 \%$ & & Other & $8.3 \%$ \\
\hline
\end{tabular}

This table presents information regarding the counterparty for trades executed on the day of the RBA monetary policy announcement. Panel A shows data for all trades on the announcement day, with the left most column depicting the counterparty for all retail and institutional trades, while the right most columns show the counterparty for trades initiated by retail and institutional investors. Panel B shows similar information but only for the 5-minute period (14:3014:35) following the RBA announcement.

The sample period includes the RBA announcement days that occur during the period 05 December 2007 - 02 December 
Table 5

The pattern of order aggressiveness in the period surrounding RBA target rate announcements for different sized firms

\begin{tabular}{|c|c|c|c|c|c|c|c|c|c|c|c|c|c|c|c|c|c|}
\hline \multirow{2}{*}{$\begin{array}{l}\text { Panel A: Institutional Orders } \\
\text { Interval } \\
\end{array}$} & \multicolumn{6}{|c|}{ Order Aggressiveness Level } & \multirow{2}{*}{$\mathrm{MO}$} & \multirow{2}{*}{ LO } & \multirow{2}{*}{$\begin{array}{c}\text { Panel B: Retail Orders } \\
\text { Interval }\end{array}$} & \multicolumn{6}{|c|}{ Order Aggressiveness Level } & \multirow[b]{2}{*}{$\mathrm{MO}$} & \multirow{2}{*}{ LO } \\
\hline & 1 & 2 & 3 & 4 & 5 & 6 & & & & 1 & 2 & 3 & 4 & 5 & 6 & & \\
\hline Large-Cap & & & & & & & & & Large-Cap & & & & & & & & \\
\hline $14: 28-14: 29$ & 0.022 & 0.021 & 0.036 & 0.005 & 0.383 & 0.534 & 0.078 & 0.922 & $14: 28-14: 29$ & 0.029 & 0.059 & 0.081 & 0.007 & 0.411 & 0.414 & 0.169 & 0.831 \\
\hline $14: 29-14: 30$ & 0.018 & 0.019 & 0.033 & 0.009 & 0.362 & 0.559 & 0.070 & 0.930 & $14: 29-14: 30$ & 0.054 & 0.041 & 0.091 & 0.018 & 0.361 & 0.436 & 0.186 & 0.814 \\
\hline $14: 30-14: 31$ & 0.025 & 0.030 & 0.052 & 0.017 & 0.501 & 0.375 & 0.107 & 0.893 & 14:30-14:31 & 0.067 & 0.049 & 0.084 & 0.036 & 0.355 & 0.410 & 0.200 & 0.800 \\
\hline $14: 31-14: 32$ & 0.020 & 0.041 & 0.067 & 0.012 & 0.412 & 0.449 & 0.127 & 0.873 & $14: 31-14: 32$ & 0.043 & 0.044 & 0.071 & 0.035 & 0.381 & 0.427 & 0.157 & 0.843 \\
\hline $14: 32-14: 33$ & 0.030 & 0.024 & 0.045 & 0.010 & 0.475 & 0.418 & 0.098 & 0.902 & $14: 32-14: 33$ & 0.055 & 0.063 & 0.053 & 0.029 & 0.371 & 0.429 & 0.171 & 0.829 \\
\hline $14: 33-14: 34$ & 0.021 & 0.027 & 0.029 & 0.007 & 0.355 & 0.562 & 0.076 & 0.924 & $14: 33-14: 34$ & 0.044 & 0.060 & 0.067 & 0.026 & 0.415 & 0.387 & 0.172 & 0.828 \\
\hline $14: 34-14: 35$ & 0.032 & 0.035 & 0.032 & 0.007 & 0.524 & 0.369 & 0.100 & 0.900 & $14: 34-14: 35$ & 0.057 & 0.039 & 0.082 & 0.020 & 0.385 & 0.416 & 0.178 & 0.822 \\
\hline Mid-Cap & & & & & & & & & Mid-Cap & & & & & & & & \\
\hline $14: 28-14: 29$ & 0.084 & 0.063 & 0.081 & 0.009 & 0.470 & 0.292 & 0.229 & 0.771 & $14: 28-14: 29$ & 0.056 & 0.040 & 0.080 & 0.012 & 0.313 & 0.499 & 0.175 & 0.825 \\
\hline $14: 29-14: 30$ & 0.028 & 0.046 & 0.042 & 0.023 & 0.500 & 0.360 & 0.117 & 0.883 & $14: 29-14: 30$ & 0.037 & 0.056 & 0.129 & 0.008 & 0.444 & 0.326 & 0.222 & 0.778 \\
\hline $14: 30-14: 31$ & 0.030 & 0.043 & 0.038 & 0.013 & 0.503 & 0.373 & 0.111 & 0.889 & $14: 30-14: 31$ & 0.025 & 0.072 & 0.042 & 0.085 & 0.295 & 0.481 & 0.139 & 0.861 \\
\hline $14: 31-14: 32$ & 0.021 & 0.029 & 0.042 & 0.020 & 0.486 & 0.401 & 0.092 & 0.908 & $14: 31-14: 32$ & 0.058 & 0.077 & 0.053 & 0.048 & 0.342 & 0.421 & 0.189 & 0.811 \\
\hline $14: 32-14: 33$ & 0.053 & 0.040 & 0.049 & 0.013 & 0.496 & 0.349 & 0.143 & 0.857 & $14: 32-14: 33$ & 0.041 & 0.035 & 0.034 & 0.048 & 0.324 & 0.518 & 0.110 & 0.890 \\
\hline $14: 33-14: 34$ & 0.024 & 0.038 & 0.041 & 0.017 & 0.524 & 0.356 & 0.103 & 0.897 & $14: 33-14: 34$ & 0.044 & 0.061 & 0.057 & 0.039 & 0.383 & 0.415 & 0.163 & 0.837 \\
\hline $14: 34-14: 35$ & 0.080 & 0.044 & 0.036 & 0.009 & 0.465 & 0.367 & 0.160 & 0.840 & $14: 34-14: 35$ & 0.029 & 0.082 & 0.050 & 0.037 & 0.399 & 0.402 & 0.162 & 0.838 \\
\hline Small-Cap & & & & & & & & & Small-Cap & & & & & & & & \\
\hline $14: 28-14: 29$ & 0.034 & 0.019 & 0.029 & 0.026 & 0.488 & 0.405 & 0.082 & 0.918 & $14: 28-14: 29$ & 0.021 & 0.050 & 0.015 & 0.002 & 0.436 & 0.476 & 0.086 & 0.914 \\
\hline $14: 29-14: 30$ & 0.042 & 0.041 & 0.048 & 0.021 & 0.455 & 0.393 & 0.131 & 0.869 & $14: 29-14: 30$ & 0.032 & 0.057 & 0.040 & 0.006 & 0.558 & 0.307 & 0.129 & 0.871 \\
\hline 14:30-14:31 & 0.024 & 0.022 & 0.059 & 0.015 & 0.480 & 0.401 & 0.105 & 0.895 & 14:30-14:31 & 0.034 & 0.036 & 0.115 & 0.022 & 0.268 & 0.524 & 0.186 & 0.814 \\
\hline $14: 31-14: 32$ & 0.021 & 0.052 & 0.022 & 0.048 & 0.492 & 0.364 & 0.095 & 0.905 & $14: 31-14: 32$ & 0.015 & 0.044 & 0.167 & 0.028 & 0.411 & 0.335 & 0.226 & 0.774 \\
\hline $14: 32-14: 33$ & 0.026 & 0.068 & 0.018 & 0.015 & 0.581 & 0.293 & 0.111 & 0.889 & $14: 32-14: 33$ & 0.009 & 0.049 & 0.020 & 0.006 & 0.404 & 0.512 & 0.078 & 0.922 \\
\hline $14: 33-14: 34$ & 0.029 & 0.029 & 0.060 & 0.013 & 0.515 & 0.354 & 0.118 & 0.882 & $14: 33-14: 34$ & 0.026 & 0.019 & 0.069 & 0.007 & 0.517 & 0.362 & 0.114 & 0.886 \\
\hline $14: 34-14: 35$ & 0.044 & 0.042 & 0.018 & 0.020 & 0.465 & 0.412 & 0.103 & 0.897 & $14: 34-14: 35$ & 0.019 & 0.007 & 0.048 & 0.012 & 0.253 & 0.662 & 0.074 & 0.926 \\
\hline
\end{tabular}

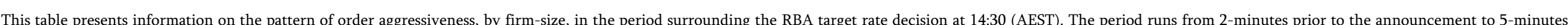

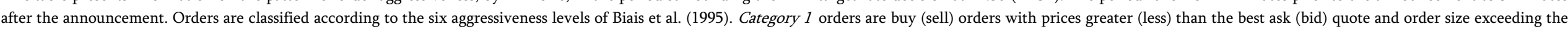

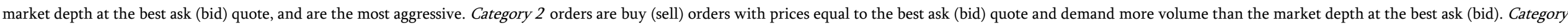

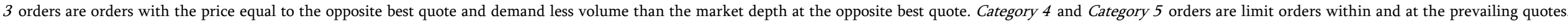

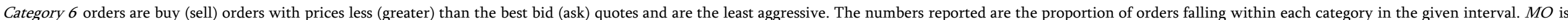

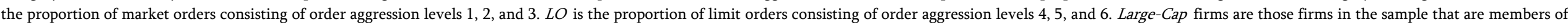

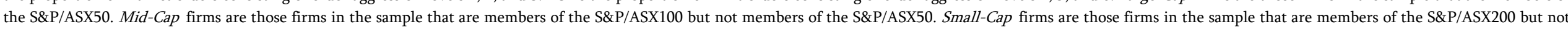
members of the S\&P/ASX100.

The sample period includes the RBA announcement days that occur during the period 05 December 2007 - 02 December 2014 
Table 6

The pattern of order aggressiveness in the period surrounding RBA target rate announcements for financial and non-financial firms

\begin{tabular}{|c|c|c|c|c|c|c|c|c|c|c|c|c|c|c|c|c|c|}
\hline \multirow{2}{*}{$\begin{array}{c}\text { Panel A: Institutional Orders } \\
\text { Interval }\end{array}$} & \multicolumn{6}{|c|}{ Order Aggressiveness Level } & \multirow{2}{*}{$\mathrm{MO}$} & \multirow{2}{*}{$\mathrm{LO}$} & \multirow{2}{*}{$\begin{array}{c}\text { Panel B: Retail Orders } \\
\text { Interval } \\
\end{array}$} & \multicolumn{6}{|c|}{ Order Aggressiveness Level } & \multirow{2}{*}{ MO } & \multirow{2}{*}{$\mathrm{LO}$} \\
\hline & 1 & 2 & 3 & 4 & 5 & 6 & & & & 1 & 2 & 3 & 4 & 5 & 6 & & \\
\hline Financial & & & & & & & & & Financial & & & & & & & & \\
\hline $14: 28-14: 29$ & 0.043 & 0.009 & 0.060 & 0.008 & 0.421 & 0.459 & 0.112 & 0.888 & $14: 28-14: 29$ & 0.050 & 0.016 & 0.067 & 0.016 & 0.384 & 0.468 & 0.132 & 0.868 \\
\hline 14:29-14:30 & 0.042 & 0.008 & 0.052 & 0.009 & 0.410 & 0.479 & 0.103 & 0.897 & $14: 29-14: 30$ & 0.044 & 0.021 & 0.061 & 0.023 & 0.370 & 0.482 & 0.126 & 0.874 \\
\hline 14:30-14:31 & 0.038 & 0.010 & 0.047 & 0.005 & 0.383 & 0.517 & 0.095 & 0.905 & 14:30-14:31 & 0.058 & 0.020 & 0.055 & 0.052 & 0.370 & 0.445 & 0.133 & 0.867 \\
\hline $14: 31-14: 32$ & 0.040 & 0.010 & 0.048 & 0.014 & 0.397 & 0.491 & 0.098 & 0.902 & $14: 31-14: 32$ & 0.056 & 0.017 & 0.060 & 0.047 & 0.399 & 0.421 & 0.133 & 0.867 \\
\hline $14: 32-14: 33$ & 0.037 & 0.011 & 0.045 & 0.013 & 0.403 & 0.490 & 0.093 & 0.907 & $14: 32-14: 33$ & 0.053 & 0.020 & 0.047 & 0.029 & 0.408 & 0.442 & 0.121 & 0.879 \\
\hline $14: 33-14: 34$ & 0.036 & 0.010 & 0.046 & 0.014 & 0.410 & 0.483 & 0.092 & 0.908 & $14: 33-14: 34$ & 0.055 & 0.016 & 0.048 & 0.034 & 0.386 & 0.460 & 0.119 & 0.881 \\
\hline $14: 34-14: 35$ & 0.044 & 0.009 & 0.046 & 0.011 & 0.406 & 0.484 & 0.098 & 0.902 & 14:34-14:35 & 0.051 & 0.017 & 0.051 & 0.036 & 0.396 & 0.448 & 0.120 & 0.880 \\
\hline Non-Financial & & & & & & & & & Non-Financial & & & & & & & & \\
\hline 14:28-14:29 & 0.033 & 0.009 & 0.056 & 0.009 & 0.428 & 0.464 & 0.099 & 0.901 & 14:28-14:29 & 0.064 & 0.019 & 0.067 & 0.020 & 0.314 & 0.517 & 0.150 & 0.850 \\
\hline 14:29-14:30 & 0.037 & 0.009 & 0.054 & 0.010 & 0.421 & 0.469 & 0.101 & 0.899 & 14:29-14:30 & 0.060 & 0.022 & 0.078 & 0.019 & 0.288 & 0.532 & 0.160 & 0.840 \\
\hline 14:30-14:31 & 0.027 & 0.010 & 0.049 & 0.014 & 0.407 & 0.493 & 0.086 & 0.914 & $14: 30-14: 31$ & 0.074 & 0.023 & 0.072 & 0.048 & 0.302 & 0.481 & 0.169 & 0.831 \\
\hline 14:31-14:32 & 0.031 & 0.011 & 0.046 & 0.015 & 0.419 & 0.478 & 0.088 & 0.912 & $14: 31-14: 32$ & 0.059 & 0.025 & 0.058 & 0.049 & 0.312 & 0.497 & 0.142 & 0.858 \\
\hline $14: 32-14: 33$ & 0.037 & 0.010 & 0.040 & 0.013 & 0.416 & 0.484 & 0.087 & 0.913 & $14: 32-14: 33$ & 0.061 & 0.021 & 0.057 & 0.031 & 0.317 & 0.512 & 0.140 & 0.860 \\
\hline $14: 33-14: 34$ & 0.036 & 0.009 & 0.043 & 0.014 & 0.416 & 0.481 & 0.089 & 0.911 & 14:33-14:34 & 0.066 & 0.020 & 0.054 & 0.037 & 0.318 & 0.505 & 0.141 & 0.859 \\
\hline $14: 34-14: 35$ & 0.034 & 0.009 & 0.043 & 0.011 & 0.424 & 0.479 & 0.086 & 0.914 & 14:34-14:35 & 0.060 & 0.020 & 0.068 & 0.028 & 0.325 & 0.499 & 0.148 & 0.852 \\
\hline
\end{tabular}

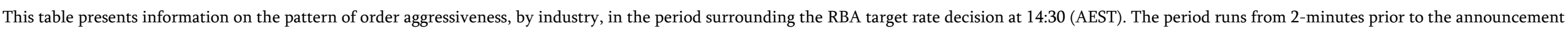

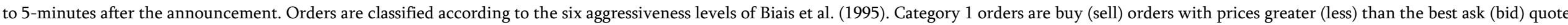

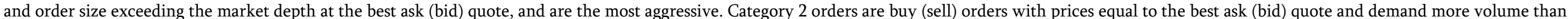

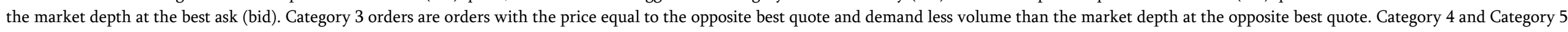

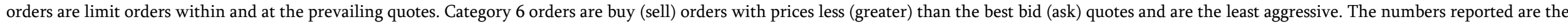

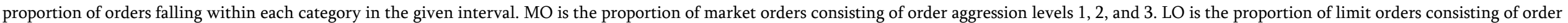
aggression levels 4, 5, and 6. Firms are categorized as financial or non-financial on the basis of the 2-digit GICS sector code.

The sample period includes the RBA announcement days that occur during the period 05 December 2007 - 02 December 2014. 
Table 7

The determinants of order aggression on days with RBA monetary policy announcements

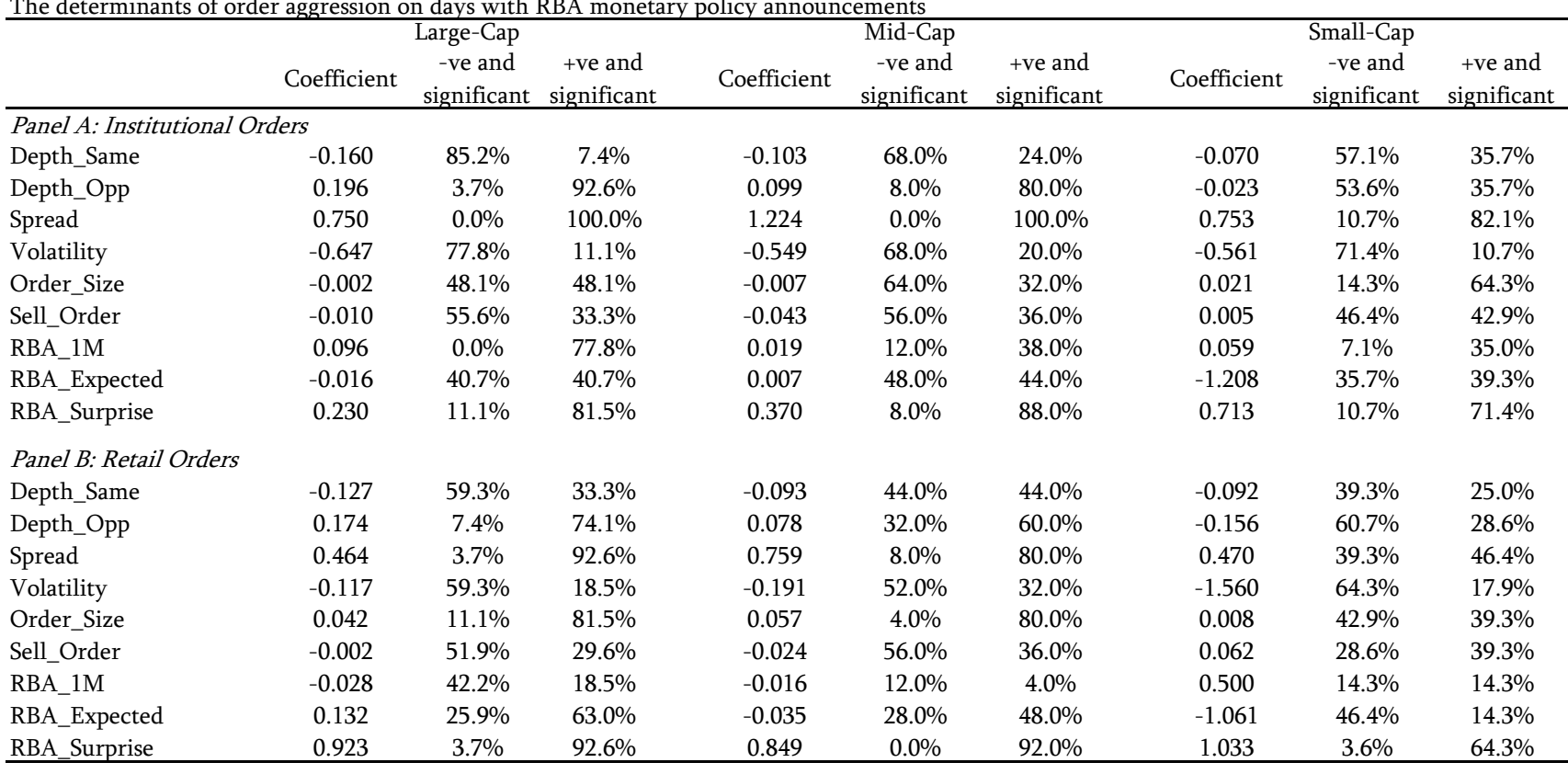

This table presents results for the ordered probit analysis of the determinants of order aggression for instituional and retail brokers on days with RBA target rate announcements. The estimated ordered probit model is: $Z_{k}=\beta_{1}$ Depth_Same ${ }_{k}+\beta_{2}$ Depth_Opp $_{k}+\beta_{3}$ Spread $_{k}+\beta_{4}$ Volatility $_{k}+$ $\beta_{5}$ Order_Size $_{k}+\beta_{6}$ Sell_Order $_{k}+\beta_{7} R B A_{-} 1 M_{k}+\beta_{8} R B A \_$Expected $_{k}+\beta_{9} R B A \_$Surprise $_{k}+\varepsilon_{k}$, where $Z_{k}$ is the latent order aggressiveness. A number of market variables are included: Depth_Same ${ }_{k}$ is the natural logarithm of the same-side market depth, Depth_Opp ${ }_{k}$ is the natural logarithm of the opposite-side market depth, Spread $_{k}$ is the relative spread at the time of the order submission, Volatility ${ }_{k}$ is the standard deviation of mid-quote returns for the 20 quotes proceeding the order, Order_Size ${ }_{k}$ is the natural logarithm of the number of shares in the order, Sell_Order $k$ is a dummy variable indicating whether the order is a sell order (1) or not (0). A number of variables relating to the RBA announcement are also included: $R B A_{-} 1 M_{k}$ is a dummy variable indicating whether the order is placed within the first minute immediately following the RBA decision (1) or not (0), $R B A \_$Expected $_{k}$ indicates the market expectations on the RBA targer rate decision, and RBA_Surprise ${ }_{k}$ indicates the level of the target rate surprise (taking a value of 0 prior to the announcement time). Robust errors are used. Large-Cap firms are members of the S\&P/ASX50, Mid-Cap firms are members of the S\&P/ASX100 but not the S\&P/ASX50, Small-Cap firms are members of the S\&P/ASX200 but not the S\&P/ASX100. -ve and significant represents the proportion of firms with a coefficient that is significantly less than zero at the $1 \%$ level, where the total number of firms in each size category is 30 . Likewise, +ve and significant is the proportion of firms with a coefficient that is significantly greater than zero at the $1 \%$ level.

The sample period includes all regular trading hours on days with RBA monetary policy announcements that occur during the period 05 December 2007 - 02 December 2014. 
Table 8

The determinants of institutional and retail buy and sell order aggression on days with RBA monetary policy announcements

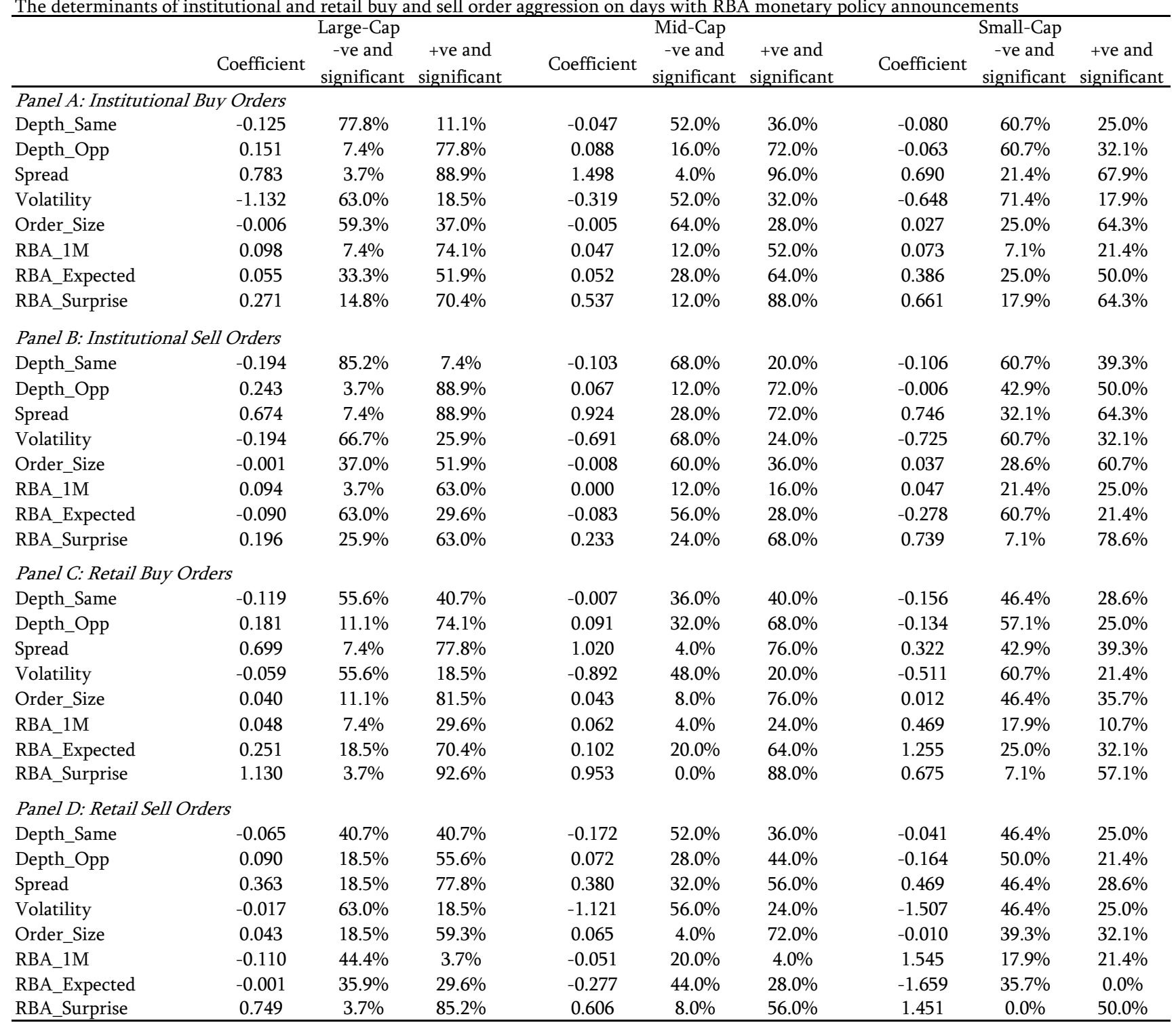

This table presents results for the ordered probit analysis of the determinants of the order aggression of the buy and sell orders of institutional and retail brokers on days with RBA target rate announcements. The estimated ordered probit model is: $Z_{k}=\beta_{1}$ Depth_Same ${ }_{k}+$

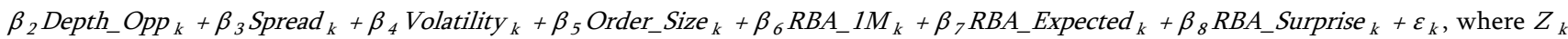
is the latent order aggressiveness. A number of market variables are included: Depth_Same ${ }_{k}$ is the natural logarithm of the same-side market depth, Depth_OPp $p_{k}$ is the natural logarithm of the opposite-side market depth, Spread ${ }_{k}$ is the relative spread at the time of the order submission, Volatility ${ }_{k}$ is the standard deviation of mid-quote returns for the 20 quotes proceeding the order, Order_Size ${ }_{k}$ is the natural logarithm of the number of shares in the order. A number of variables relating to the RBA announcement are also included: $R B A_{-} 1 M_{k}$ is a dummy variable indicating whether the order is placed within the first minute immediately following the RBA decision (1) or not (0), RBA_Expected ${ }_{k}$ indicates the market expectations on the RBA targer rate decision, and RBA_Surprise ${ }_{k}$ indicates the level of the target rate surprise (taking a value of 0 prior to the announcement time). Robust errors are used. Large-Cap firms are members of the S\&P/ASX50, MidCap firms are members of the S\&P/ASX100 but not the S\&P/ASX50, Small-Cap firms are members of the S\&P/ASX200 but not the S\&P/ASX100. -ve and significant represents the proportion of firms with a coefficient that is significantly less than zero at the $1 \%$ level, where the total number of firms in each size category is 30. Likewise, tve and significant is the proportion of firms with a coefficient that is significantly greater than zero at the $1 \%$ level.

The sample period includes all regular trading hours on days with RBA monetary policy announcements that occur during the period 05 December 2007 - 02 December 2014. 
Table 9

The price impact of retail broker trades

\begin{tabular}{|c|c|c|c|}
\hline & $\begin{array}{c}\text { Interval } \\
\text { (secs after RBA) }\end{array}$ & $\begin{array}{c}\mid \text { Mean Return (\%) } \mid \\
(\%)\end{array}$ & $\mathrm{N}$ \\
\hline \multicolumn{4}{|l|}{ All Firms } \\
\hline & $(0,10)$ & 0.88 & 5432 \\
\hline Group 1 & $(0,60)$ & 0.67 & 5432 \\
\hline & $(0,300)$ & 2.71 & 5432 \\
\hline & $(0,10)$ & 3.70 & 1185 \\
\hline Group 2 & $(0,60)$ & 3.37 & 1185 \\
\hline & $(0,300)$ & 3.42 & 1185 \\
\hline \multicolumn{4}{|l|}{ Large-Cap } \\
\hline & $(0,10)$ & 1.05 & 3722 \\
\hline Group 1 & $(0,60)$ & 0.78 & 3722 \\
\hline & $(0,300)$ & 2.40 & 3722 \\
\hline & $(0,10)$ & 4.70 & 894 \\
\hline Group 2 & $(0,60)$ & 4.27 & 893 \\
\hline & $(0,300)$ & 3.35 & 893 \\
\hline \multicolumn{4}{|l|}{ Mid-Cap } \\
\hline & $(0,10)$ & 0.58 & 1396 \\
\hline Group 1 & $(0,60)$ & 0.50 & 1396 \\
\hline & $(0,300)$ & 3.27 & 1396 \\
\hline & $(0,10)$ & 0.64 & 242 \\
\hline Group 2 & $(0,60)$ & 0.61 & 242 \\
\hline & $(0,300)$ & 3.55 & 242 \\
\hline \multicolumn{4}{|l|}{ Small-Cap } \\
\hline & $(0,10)$ & 1.93 & 314 \\
\hline Group 1 & $(0,60)$ & 1.65 & 314 \\
\hline & $(0,300)$ & 3.94 & 314 \\
\hline & $(0,10)$ & 4.52 & 49 \\
\hline Group 2 & $(0,60)$ & 5.57 & 49 \\
\hline & $(0,300)$ & 4.03 & 49 \\
\hline
\end{tabular}

This table presents results for the price impact of trades initiated by retail brokers in the immediate aftermath of RBA announcements (measured as absolute returns following trade initation). The period of returns is measured in seconds following the announcement. Trades in Group 1 are those initiated by a retail broker with an insitutional broker as counterparty. Trades in Group 2 are those initiated by a retail broker with a non-instituional broker as a counterparty. Large-Cap firms are members of the S\&P/ASX50, Mid-Cap firms are members of the S\&P/ASX100 but not the S\&P/ASX50, Small-Cap firms are members of the S\&P/ASX200 but not the S\&P/ASX100. Absolute returns are calculated using the quote mid-point at the end of the relevant time interval.

The sample period includes the RBA announcement days that occur during the period 05 December 2007 - 02 December 2014. 